\title{
CFD modeling of reactive pollutant dispersion in simplified urban configurations with different chemical mechanisms
}

\author{
Beatriz Sanchez ${ }^{1}$, Jose-Luis Santiago ${ }^{1}$, Alberto Martilli ${ }^{1}$, Magdalena Palacios ${ }^{1}$, and Frank Kirchner ${ }^{2}$ \\ ${ }^{1}$ Research Center for Energy, Environment and Technology (CIEMAT), Madrid, Spain \\ ${ }^{2}$ GAIASENS Technologies, Sarl, Switzerland
}

Correspondence to: Beatriz Sanchez (beatriz.sanchez@ciemat.es)

Received: 8 March 2016 - Published in Atmos. Chem. Phys. Discuss.: 27 May 2016

Revised: 2 September 2016 - Accepted: 11 September 2016 - Published: 28 September 2016

\begin{abstract}
An accurate understanding of urban air quality requires considering a coupled behavior between the dispersion of reactive pollutants and atmospheric dynamics. Currently, urban air pollution is mostly dominated by traffic emission, where nitrogen oxides $\left(\mathrm{NO}_{x}\right)$ and volatile organic compounds (VOCs) are the primary emitted pollutants. However, modeling reactive pollutants with a large set of chemical reactions, using a computational fluid dynamic (CFD) model, requires a large amount of computational (CPU) time. In this sense, the selection of the chemical reactions needed in different atmospheric conditions becomes essential in finding the best compromise between CPU time and accuracy. The purpose of this work is to assess the differences in $\mathrm{NO}$ and $\mathrm{NO}_{2}$ concentrations by considering three chemical approaches: (a) passive tracers (non-reactive), (b) the $\mathrm{NO}_{x}-\mathrm{O}_{3}$ photostationary state and (c) a reduced complex chemical mechanism based on 23 species and 25 reactions. The appraisal of the effects of chemical reactions focuses on studying the $\mathrm{NO}$ and $\mathrm{NO}_{2}$ dispersion in comparison with the tracer behavior within the street. In turn, the effect of including VOC reactions is also analyzed taking into account several VOC $/ \mathrm{NO}_{x}$ ratios of traffic emission. Given that the $\mathrm{NO}$ and $\mathrm{NO}_{2}$ dispersion can also be affected by atmospheric conditions, such as wind flow or the background concentration from season-dependent pollutants, in this work the influence of wind speeds and background $\mathrm{O}_{3}$ concentrations are studied. The results show that the presence of ozone in the street plays an important role in $\mathrm{NO}$ and $\mathrm{NO}_{2}$ concentrations. Therefore, greater differences linked to the chemical approach used are found with higher $\mathrm{O}_{3}$ concentrations and faster wind speeds. This bears relation to the vertical flux as a function of ambient wind speed since it increases the
\end{abstract}

pollutant exchange between the street and the overlying air. This detailed study allows one to ascertain under which atmospheric conditions the inclusion of chemical reactions are necessary for the study of $\mathrm{NO}$ and $\mathrm{NO}_{2}$ dispersion. The conclusions can be applied to future studies in order to establish the chemical reactions needed in terms of an accurate modeling of $\mathrm{NO}$ and $\mathrm{NO}_{2}$ dispersion and the $\mathrm{CPU}$ time required in a real urban area.

\section{Introduction}

Urban air pollution is currently a serious environmental problem. The non-uniformity in the building distribution in a city involves complex flow patterns and, therein, heterogeneous pollutant dispersion within the streets. In addition, the high levels of detrimental pollutants in urban areas are mostly dominated by traffic emission. The main related traffic pollutants are $\mathrm{NO}_{x}$ (nitrogen oxides; $\mathrm{NO}+\mathrm{NO}_{2}$ ), $\mathrm{CO}$, hydrocarbons and particles. But given the proximity between sources and receptors in the street, only the fastest chemical reactions have an impact on pollutant concentrations. Therefore, some slow reactive compounds like $\mathrm{CO}$ or hydrocarbons can be considered as practically inert species at microscale. However, the $\mathrm{NO}_{2}$ dissociation in the presence of light and the $\mathrm{NO}$ titration by reduction of $\mathrm{O}_{3}$ take place rather fast (Vardoulakis et al., 2003). Furthermore, volatile organic compounds (VOCs) are also involved in this complex chain of reactions.

Currently, modeling urban air quality using a computational fluid dynamic (CFD) model is a big challenge. Besides pollutant dispersion, the simulation of chemical conversions 
of reactive pollutants in complex urban areas increases the computational time considerably. To better understand the problem, it is first necessary to thoroughly study the basic dynamical effects controlling non-reactive pollutant dispersion in simplified geometries. Many previous studies have investigated the main factors that affect the passive tracers distribution within the canopy such as the inflow conditions (Tominaga and Stathopoulos, 2010; Kim and Baik, 2004), the street-canyon aspect ratio (Chang and Meroney, 2003), thermal effects of a heating surface (Park et al., 2012) or the vegetation location in the street (Buccolieri et al., 2011).

However, the main pollutants in an urban area are largely reactive compounds and for that reason, a photostationary scheme was included in an attempt to examine the dispersion of pollutants in street canyons. Baker et al. (2004) and Baik et al. (2007) studied the dispersion of reactive pollutants in a street canyon considering the $\mathrm{NO}_{x}-\mathrm{O}_{3}$ photostationary steady state. Baik et al. (2007) also incorporated a heating surface at the bottom of the street and found that the magnitude of the chemical term for $\mathrm{O}_{3}$ was comparable to the advection or turbulent diffusion terms, but that was not the case either for $\mathrm{NO}$ or for $\mathrm{NO}_{2}$. Both researches showed that the $\mathrm{O}_{3}$ concentration was depleted faster within the canopy because of the high NO emission at ground level. These studies underlined the importance of including the $\mathrm{O}_{3}$ photochemical reaction in order to analyze the $\mathrm{NO}$ and $\mathrm{NO}_{2}$ dispersion.

In addition, the VOCs related to traffic emission are also involved in urban air pollution. This becomes necessary to model a vast number of chemical interactions $\left(\mathrm{NO}, \mathrm{NO}_{2}, \mathrm{O}_{3}\right.$ and VOCs). In more recent studies, complex chemical mechanisms have been implemented in CFD models in order to reproduce the $\mathrm{NO}$ and $\mathrm{NO}_{2}$ dispersion in a street canyon. Kwak and Baik (2012) developed a CFD model coupled with the carbon bond mechanism IV (CBM-IV) and they evaluated the $\mathrm{O}_{3}$ sensitivity with respect to different VOC and $\mathrm{NO}_{x}$ emission levels in a street canyon. They found that the $\mathrm{O}_{3}$ removal from the $\mathrm{NO}$ reaction was more important than the $\mathrm{NO}_{2}$ photolysis given by the continuous and high $\mathrm{NO}$ emission from vehicles, which resulted in the $\mathrm{O}_{3}$ behavior having a negative correlation with $\mathrm{NO}_{x}$ emission levels. Likewise, the $\mathrm{O}_{3}$ concentration was weakly correlated with the amount of VOC emission. Kwak et al. (2013) examined the dispersion and photochemical evolution of reactive pollutants in a street canyon with different canyon aspect ratios. It confirmed the relation $\mathrm{O}_{3}$ has with $\mathrm{NO}_{x}$ and VOC emission levels, and they found a slight influence of wind speed whereby increasing the wind speed enhances the exchange with overlying air, which strengthens the downward $\mathrm{O}_{3}$ transport. These recent studies highlight the importance of the $\mathrm{O}_{3}$ oxidation process as well as the $\mathrm{OH}$ oxidation process in describing the photochemical reactions in the street. Park et al. (2015) analyzed different aspect ratios and several $\mathrm{VOC} / \mathrm{NO}_{x}$ emission scenarios in three-dimensional (3-D) street canyons. The main effects of $\mathrm{NO}_{x}$ and VOC emission levels in $\mathrm{O}_{3}$ concentration are similar to the results obtained in 2-D studies. In contrast, small variations are locally found on account of different flow patterns generated by the geometry of the domain.

To further analyze the sensitivity with the chemical mechanism used in a CFD model, Kim et al. (2012) compared the hourly concentration of $\mathrm{NO}, \mathrm{NO}_{2}$ and $\mathrm{O}_{3}$ with the photostationary steady state and a full chemical mechanism (110 species and 343 reactions) with identical conditions. The results revealed similar values of $\mathrm{NO}$ and $\mathrm{NO}_{2}$ concentrations, whereas the $\mathrm{O}_{3}$ concentration with the simple mechanism was lower than that obtained with the full scheme. Bright et al. (2013) compared the $\mathrm{O}_{3}-\mathrm{NO}_{x}$ chemical system with a full chemical mechanism (51 chemical species and 136 reactions) using a LES (large eddy simulation ) model. They studied in depth the effects of VOC chemical processes and found that by means of a more detailed chemistry, the values of $\mathrm{NO}, \mathrm{NO}_{2}$ and $\mathrm{O}_{3}$ differ from the photostationary steady state, which reflects additional transformation of $\mathrm{NO}$ into $\mathrm{NO}_{2}$ resulting from the intrinsic VOC degradation processes.

The coupled behavior between chemistry and dynamic processes is also a research goal. The relative importance of chemistry vs. turbulent transport has also been investigated for homogeneous surface layers in the past (Galmarini et al., 1997; Molemaker and Vilà-Guerau de Arellano, 1998). The relative differences between turbulent and chemical timescales were evaluated using the Damkholer number. However, we estimate that this approach is not appropriate in the urban canopy layer (UCL). Basically because the transport is not only turbulent (as it is in the homogeneous surface layer), but also driven by the mean motions induced by the presence of the obstacles. Instead of adding a new timescale - linked to the mean transport - and trying to deal with the strong heterogeneity of the flow and associated timescales typical of the UCL, we found it more straightforward to perform simulations with and without chemical reactions, and to assess the relative importance of chemistry based on the difference between the simulations. In turn, regarding the chemical scheme used, the best compromise between accuracy and computational time required is also part of the main conclusions since a complex chemical scheme implies more than twice the CPU time needed for the photostationary steady state.

Therefore, the aim of this work is to ascertain under which conditions the incorporation of more chemical reactions is required in order to model the dispersion of $\mathrm{NO}$ and $\mathrm{NO}_{2}$ in the urban canopy. To achieve this goal, the $\mathrm{NO}$ and $\mathrm{NO}_{2}$ dispersion is studied in two simplified geometries (2-D and 3-D geometries) under different chemical approaches: (a) non-reactive, (b) with photostationary steady state and (c) with a reduced complex chemical scheme (25 reactions and 23 species). In addition, knowing the impact of atmospheric conditions on reactive pollutant dispersions, effects of the background $\mathrm{O}_{3}$ concentrations, the wind speed and the $\mathrm{VOC} / \mathrm{NO}_{x}$ emission ratio are jointly assessed. 


\section{Chemical schemes used}

The evaluation of $\mathrm{NO}$ and $\mathrm{NO}_{2}$ dispersion regarded as reactive pollutants is studied here using two chemical schemes: the photostationary steady state and a reduced complex chemical scheme and a reduced complex chemical mechanism developed for this study (hereafter referred as CCMCFD). The photostationary steady state is the most simple chemical mechanism implemented in CFD and it is defined by a three-reaction system of $\mathrm{NO}, \mathrm{NO}_{2}$ and $\mathrm{O}_{3}$.

$\mathrm{NO}_{2}+h v \longrightarrow \mathrm{NO}+\mathrm{O}$,

$\mathrm{O}+\mathrm{O}_{2}+M \longrightarrow \mathrm{O}_{3}+M$,

$\mathrm{O}_{3}+\mathrm{NO} \longrightarrow \mathrm{NO}_{2}+\mathrm{O}_{2}$,

where $M$ represents a molecule that absorbs excess energy and thereby stabilizes $\mathrm{O}_{3}$ molecules formed (Seinfeld and Pandis, 1998). In the photochemical reaction, the photolysis rate constant is dependent on zenith angle $(\theta)$ and it is defined as $J_{\mathrm{NO}_{2}}=A \exp (B / \cos (\theta))$, where $A$ and $B$ are chemical constants.

The complex chemical scheme used, which involves the VOC interactions, needs to be as reduced as much as possible due to the large load of computational time required to simulate a vast number of chemical reactions using CFD modeling and the number of simulations needed to carry out this detailed study. The aim was to reduce the regional atmospheric chemistry mechanism (RACM) - with 77 species and 237 reactions (Stockwell et al., 1997) - as far as possible without losing much accuracy during the first $30 \mathrm{~min}$ of simulation for urban conditions in a box model. The CCM-CFD was created applying the software CHEMATA (CHEmical Mechanism Adaptation to Tropospheric Applications) (Junier et al., 2005; Kirchner, 2005). A wide set of different urban pollution conditions was investigated and special emphasis was given to cases where the results for the RACM mechanism differ considerable from the results of the photostationary steady state. Three main manners of mechanism reduction are applied:

- Modification of the lumping groups: several chemical similar RACM lumping groups are united to a new lumping group. For example, the RACM alkanes ETH, HC3, HC5 and HC8 are summed up in the new species ALK. The RACM olefins ETE, OLT, OLI are lumped to the new species OLE and the RACM aromatic compounds TOL and XYL are integrated in the new species ARO.

- Modification of the organic peroxy radical parameterization: instead of using the $20 \mathrm{RACM} \mathrm{RO} 2$ species, we applied the approach described by Kirchner (2005) with the $\mathrm{RO}_{2}$ species $\mathrm{CH}_{3} \mathrm{O}_{2}$ (called $\mathrm{MO}_{2}$ ) and $\mathrm{RC}(\mathrm{O}) \mathrm{O}_{2}$ (called $\mathrm{ACO}_{3}$ ) as well as the two operator species $\mathrm{XO}_{2}$ and $\mathrm{XO}_{2} \mathrm{~N}$, which work in the following way. The real reactions

$\mathrm{R}-\mathrm{H}+\mathrm{HO} \longrightarrow \mathrm{R}^{*}+\mathrm{H}_{2} \mathrm{O}$

$\mathrm{R}^{*}+\mathrm{O}_{2} \longrightarrow \mathrm{RO}_{2}$,

$\mathrm{RO}_{2}+\mathrm{NO} \longrightarrow a \mathrm{RONO}_{2}+b\left(\mathrm{RO}+\mathrm{NO}_{2}\right)$

$\mathrm{RO} \longrightarrow$ Products,

are parameterized by

$\mathrm{R}-\mathrm{H}+\mathrm{HO}$

$\longrightarrow a \mathrm{XO}_{2} \mathrm{~N}+b\left(\mathrm{XO}_{2}+\right.$ products $)$,

$\mathrm{XO}_{2}+\mathrm{NO} \longrightarrow \mathrm{NO}_{2}$

$\mathrm{XO}_{2} \mathrm{~N}+\mathrm{NO} \longrightarrow \mathrm{RONO}_{2}$.

- Elimination of reactions and species that are not crucial for simulating under the given conditions (timescale of about $30 \mathrm{~min}$, urban pollution conditions, daytime). Focusing on daytime simulations we can eliminate the species $\mathrm{NO}_{3}$ and all its reactions. Also, low reactive species such as $\mathrm{CH}_{4}$ and $\mathrm{H}_{2}$ can be eliminated under urban conditions.

The resulting CCM-CFD mechanism consists of 23 species and 25 chemical reactions (Table 1). Compared to the photostationary steady state, the CCM-CFD includes the peroxy radical production from VOCs, $\mathrm{CO}$ and $\mathrm{SO}_{2}$ as well as $\mathrm{NO}_{x}$ loss processes by the formation of peroxyacyl nitrates, $\mathrm{HNO}_{3}$ and organic nitrates. Whereas the peroxy radical production increases the $\mathrm{NO}_{2} / \mathrm{NO}$ ratio and therefore the $\mathrm{NO}_{2}$ concentrations, the $\mathrm{NO}_{x}$ loss processes decrease $\mathrm{NO}_{x}$ and therefore $\mathrm{NO}_{2}$. Furthermore, $\mathrm{O}_{3}$ loss by the reaction with olefins is considered. Therefore, the effect on $\mathrm{NO}$ and $\mathrm{NO}_{2}$ concentration after including the $\mathrm{O}_{3}-\mathrm{NO}_{x}$ reactions can be quantified with the deviation from the non-reactive pollutant concentration. Moreover, the influence of including reactions involving VOCs can be obtained with the differences of $\mathrm{NO}$ and $\mathrm{NO}_{2}$ concentrations between using the CCM-CFD and the photostationary steady state.

\section{CFD model description}

\subsection{Model description}

The CFD model used is based on the Reynolds-averaged Navier-Stokes (RANS) equations with a $k-\varepsilon$ turbulence model. This model allows one to evaluate the effect of several parameters using a wide set of simulations within a reasonable CPU time. The turbulence can be solved more accurately with other models, such as large-eddy simulation or direct numerical simulation; however, the CPU load increases considerably and it would limit the number of simulations. In this work, the CFD-RANS model is STAR-CCM+ (from $\mathrm{CD}$-adapco). It has been used in previous research in 
Table 1. The complex chemical mechanism (CCM-CFD): the units of the rate constants of first-order reactions are $\mathrm{s}^{-1}$ and of second-order reactions $\mathrm{cm}^{3} \mathrm{~s}^{-1}$. The rate constants for the reactions called "thermal" can be calculated by $k=A \cdot \exp [(-E / R) / T]$, of reactions called "Troe" by $k=\left\{k_{0}(T)[M]\right) /\left(1+\left(k_{0}(T)[M] / k_{\infty}(T)\right)\right\} 0.6^{\left\{1+\left[\log _{10}\left(k_{0}(T)[M] / k_{\infty}(T)\right)\right]^{2}\right\}^{-1}}$, and reactions called "Troe-equilibrium" by $k=$ $A \exp (-B / T) \times\left\{k_{0}(T)[M] /\left(1+\left(k_{0}(T)[M] / k_{\infty}(T)\right)\right)\right\} 0.6^{\left\{1+\log _{10}\left[k_{0}(T)[M] / k_{\infty}(T)\right]^{2}\right\}^{-1}}$, where $k_{0}(T)=k_{0}^{300}(T / 300)^{-n}$ and $k_{\infty}(T)=$ $k_{\infty}^{300}(T / 300)^{-m}$.

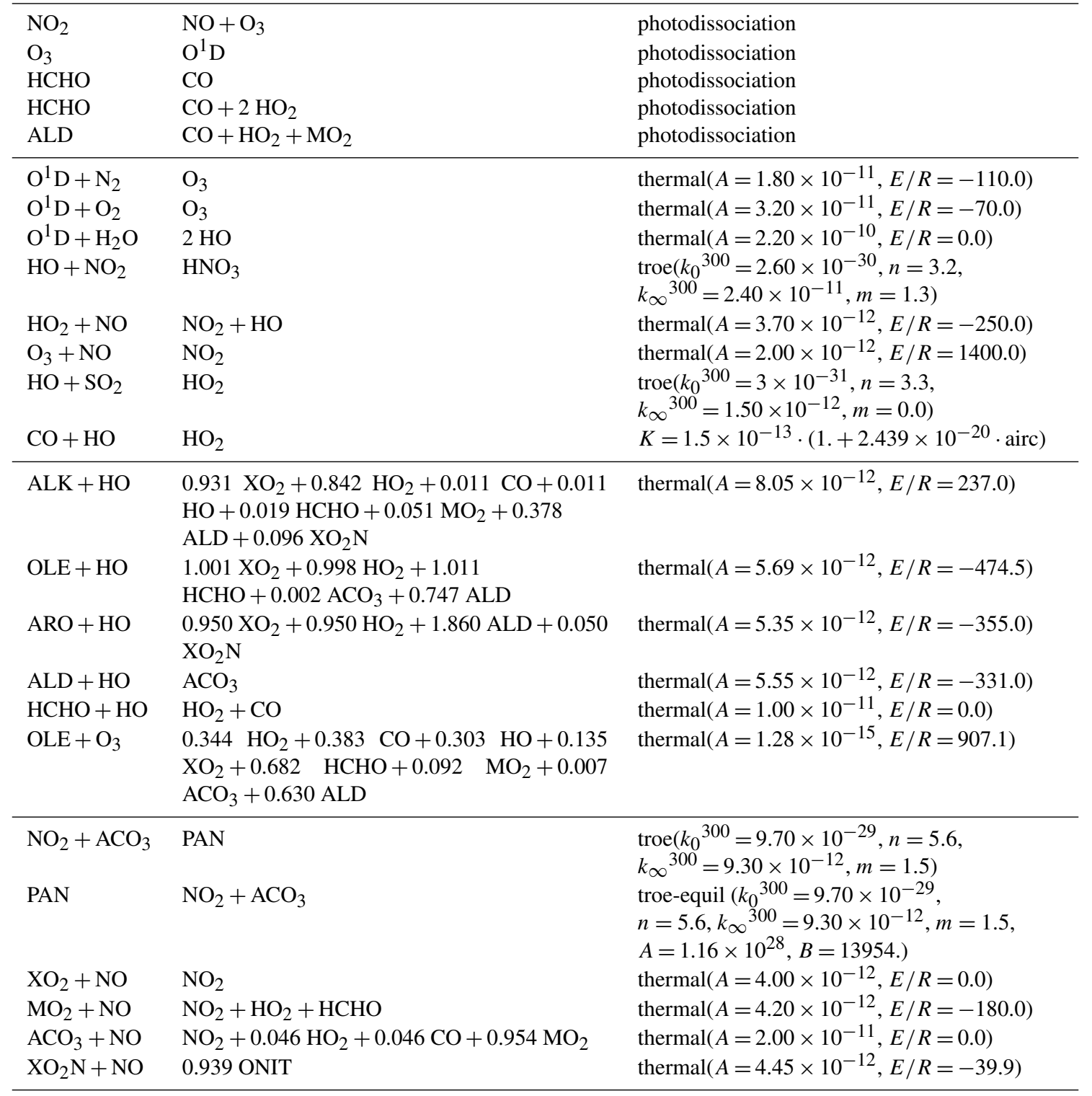

order to study dynamical processes, thermal forcing and passive tracer dispersion in simplified and real urban geometries (Santiago and Martilli, 2010; Martilli et al., 2013; Santiago et al., 2014).

The $\mathrm{NO}_{x}-\mathrm{O}_{3}$ photostationary state and the complex chemical mechanism, as described in the previous section, are implemented in the CFD model in a way that the chemical term is added to the transport equation for each pollutant. The chemical term is defined as formation and depletion of a compound in chemical reactions and modeled as a produc- tion rate in the transport equation for each chemical species $\left([\Delta C]_{\text {Chem }}\right)$. The traffic emission is added like a source term $\left(S_{C_{i}}\right)$. Hence, the transport equations are given by

$$
\begin{aligned}
\frac{\partial C_{i}}{\partial t} & +U_{i} \frac{\partial C_{i}}{\partial x_{j}}=D \frac{\partial^{2} C_{i}}{\partial x_{j} \partial x_{j}}+\frac{\partial}{\partial x_{j}}\left(K_{c} \frac{\partial C_{i}}{\partial x_{j}}\right) \\
+ & {[\Delta C]_{\text {Chem }}+S_{C_{i}}, }
\end{aligned}
$$


where $C_{i}$ is the concentration of the $i$ th species and $D$ and $K_{c}$ are molecular diffusivity and eddy diffusivity of pollutants, respectively.

\subsection{Simulation setup}

The distribution and the residence time of pollutants in the streets are mainly affected by the flow defined as a result of building configurations. The pollutant dispersion is analyzed in two types of geometries with the purpose of understanding the behavior of reactive pollutants in the street and the dependence on geometry. Figure 1 shows the computational domains used: a single street-canyon (2-D geometry) and a staggered array of cubes (3-D geometry). The domain sizes of street-canyon and staggered array of cubes are $24 \times 40 \times 64 \mathrm{~m}$ and $64 \times 64 \times 64 \mathrm{~m}$ in $x, y$ and $z$ directions, respectively. The aspect ratio defined as the ratio of building height $(H)$ to the street width $(W)$ is $H / W=1$ in both geometries. The top of the domains is fixed at $4 H$ based on the results obtained in Coceal et al. (2006). The 3-D array of cubes is represented by staggered cubes with building width $(L)$, resulting in a packing density $\lambda=0.25$. A grid independence test was carried out and the mesh resolution was selected to $1 \mathrm{~m}$ in all directions.

Symmetry boundary conditions are assumed in the spanwise direction ( $y$ direction) and cyclic boundary conditions are imposed in the streamwise direction in order to simulate an infinite number of streets. The flow is driven in $x$ direction by a pressure gradient equal to $\rho u_{\tau}^{2} / 4 H$, where $u_{\tau}$ is a reference velocity. Two velocities are studied in this work, $u_{\tau}=0.45 \mathrm{~m} \mathrm{~s}^{-1}$ and $u_{\tau}=0.23 \mathrm{~m} \mathrm{~s}^{-1}$. For $u_{\tau}=0.23 \mathrm{~m} \mathrm{~s}^{-1}$, the corresponding wind speeds at $1.5 H$ are 1.9 and $1.5 \mathrm{~m} \mathrm{~s}^{-1}$ in the 2-D and 3-D geometries, respectively, and 2 times as much for the $u_{\tau}=0.45$ case. For flow and turbulence equations, symmetry conditions are established at the top of the domain that enforce parallel flow and zero normal derivatives for the dynamic variables (Santiago and Martilli, 2010).

The traffic emission sources are located at ground level in both domains (Fig. 1). Knowing that the diurnal variation of traffic flow in an urban area registers two peaks of traffic around 08:00 LST (local standard time) and 20:00 LST and a valley around 13:00 LST, we focus on analyzing the $\mathrm{NO}$ and $\mathrm{NO}_{2}$ dispersion in maximum emission conditions at 08:00 LST. The traffic emission is simulated considering a $\mathrm{NO}_{x}$ emission of $0.5 \mathrm{~g} \mathrm{~km}^{-1}$ per vehicle (Baker et al., 2004; Baik et al., 2007) and the volumetric ratio of $\mathrm{NO}$ and $\mathrm{NO}_{2}$ emission is 10:1 (Buckingham, 1997). The emission of NO and $\mathrm{NO}_{2}$ is fixed with rates of 112 and $17 \mu \mathrm{g} \mathrm{m}^{-1} \mathrm{~s}^{-1}$, respectively, which is equivalent to 930 vehicles per hour representative of medium traffic (Baker et al., 2004). In addition, the VOC traffic emission is included by using the CCMCFD. The emitted VOC $/ \mathrm{NO}_{x}$ ratio by vehicles is dependent on several factors such as kind of vehicle or traffic flow speed. For this reason, two VOC $/ \mathrm{NO}_{x}$ emission ratios are simulated: $1 / 5$ and $1 / 2$, which are within the typical values (a)
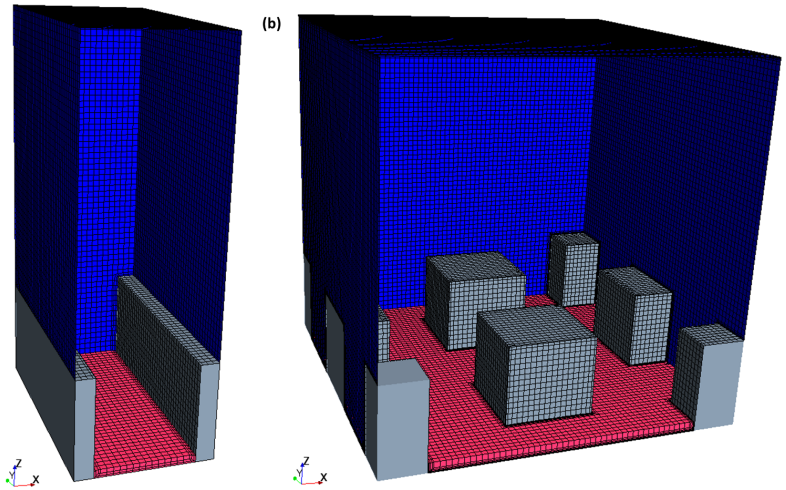

Figure 1. Illustration of the computational domains: (a) a single street canyon with $H=16 \mathrm{~m}$ and $W=16 \mathrm{~m}$ (2-D geometry), and (b) a staggered array of cubes with $H, W$ and $L$ equal to $16 \mathrm{~m}$ (3-D geometry).

of traffic emission ratios in the past few years in the city of Madrid (Ayuntamiento-Madrid, 2014). Some VOC are lumped in terms of specific functional groups in the CCMCFD. The emitted VOC species are OLE, ARO, ALK, ALD and $\mathrm{HCHO}$, and their volumetric proportions are 28.6, 23.1, 38.6, 4.0 and $5.6 \%$, respectively.

For transport equations of pollutants, constant concentrations are established as boundary conditions at the top of the domain. Due to cyclic and symmetry conditions along $x$ direction and $y$ direction, respectively, these concentrations play an important role considering chemical reactions and the background concentrations of pollutants are imposed. The values of $\mathrm{NO}, \mathrm{NO}_{2}, \mathrm{CO}$ and $\mathrm{SO}_{2}$ concentrations are fixed at 16, 35, 200 and $2 \mathrm{ppb}$, respectively, for all scenario. However, the VOC concentrations are established with the same VOC / $\mathrm{NO}_{x}$ emission ratio considered in that simulation. On the other hand, the estimation of the $\mathrm{O}_{3}$ concentration (hereafter, referred as $\left[\mathrm{O}_{3}\right]$ ) at the top is computed by the photochemical equilibrium equation:

$\left[\mathrm{O}_{3}\right]=\frac{J_{\mathrm{NO}_{2}}\left[\mathrm{NO}_{2}\right]}{k[\mathrm{NO}]}$,

where $k$ is the rate reaction constant and it is set assuming isothermal condition $(T=298 \mathrm{~K})$. With the purpose of evaluating the influence of the available $\mathrm{O}_{3}$ on $\mathrm{NO}$ and $\mathrm{NO}_{2}$ concentration (hereafter referred to as $[\mathrm{NO}]$ and $\left[\mathrm{NO}_{2}\right]$ ) within the street, two characteristic cases of opposite seasons are studied. The photolysis rate $J_{\mathrm{NO}_{2}}$ is calculated as a function of the zenith angle; hence, a representative zenith angle of winter $\left(\theta=78^{\circ}\right)$ and another one of summer $\left(\theta=46^{\circ}\right)$ are considered to compute the $\left[\mathrm{O}_{3}\right]$ established at top of the domain. The resulting background $\mathrm{O}_{3}$ concentrations are 10.6 and $39.8 \mathrm{ppb}$ for the representative cases of winter and summer, respectively.

Table 2 summarizes all simulated cases in each computational domain: 2-D and 3-D geometry. The pollutant dis- 
Table 2. Summary of all cases simulated in the 2-D and 3-D geometries. The four chemical scenarios are simulated in each atmospheric condition.

\begin{tabular}{|c|c|c|}
\hline \multicolumn{3}{|c|}{ Chemical scenarios } \\
\hline \multicolumn{3}{|c|}{ Non-reactive } \\
\hline \multicolumn{3}{|c|}{ Photostationary steady state } \\
\hline \multirow{2}{*}{\multicolumn{3}{|c|}{$\begin{array}{l}\text { CCM-CFD with VOC / NO } x=1 / 5(\mathrm{CCM} 1 / 5) \\
\text { CCM-CFD with VOC / } \mathrm{NO}_{x}=1 / 2(\mathrm{CCM} 1 / 2)\end{array}$}} \\
\hline & & \\
\hline \multicolumn{3}{|c|}{ Atmospheric conditions } \\
\hline & Background $\left[\mathrm{O}_{3}\right]$ & Reference velocity \\
\hline Case 1 & {$\left[\mathrm{O}_{3}\right]=39.8 \mathrm{ppb}$} & $u_{\tau}=0.45 \mathrm{~m} \mathrm{~s}^{-1}$ \\
\hline Case 2 & {$\left[\mathrm{O}_{3}\right]=39.8 \mathrm{ppb}$} & $u_{\tau}=0.23 \mathrm{~m} \mathrm{~s}^{-1}$ \\
\hline Case 3 & {$\left[\mathrm{O}_{3}\right]=10.6 \mathrm{ppb}$} & $u_{\tau}=0.45 \mathrm{~m} \mathrm{~s}^{-1}$ \\
\hline Case 4 & {$\left[\mathrm{O}_{3}\right]=10.6 \mathrm{ppb}$} & $u_{\tau}=0.23 \mathrm{~m} \mathrm{~s}^{-1}$ \\
\hline
\end{tabular}

persion is analyzed considering the following chemical scenarios: (a) non-reactive pollutants, (b) $\mathrm{NO}_{x}-\mathrm{O}_{3}$ photostationary state, (c) CCM-CFD with $\mathrm{VOC} / \mathrm{NO}_{x}=1 / 5$ and (d) CCM-CFD with VOC $/ \mathrm{NO}_{x}=1 / 2$; moreover, the four chemical scenarios are simulated in every atmospheric conditions combining two reference velocities $\left(u_{\tau}=0.45 \mathrm{~m} \mathrm{~s}^{-1}\right.$ and $u_{\tau}=0.23 \mathrm{~m} \mathrm{~s}^{-1}$ ) and two ozone background concentrations $\left(\left[\mathrm{O}_{3}\right]=10.6 \mathrm{ppb}\right.$ and $\left.\left[\mathrm{O}_{3}\right]=39.8 \mathrm{ppb}\right)$.

\subsection{CFD model evaluation}

Due to a lack of experimental data that can be used to evaluate the chemical mechanisms, the results from the CFD model are evaluated in two steps. First, the dispersion in the canyon using the non-reactive case is compared with experimental data (Meroney et al., 1996). Second, the implementation in the CFD model of the chemical terms as a part of the complex chemical scheme (CCM-CFD) is evaluated with the results from a chemical box model well established (Junier et al., 2005; Kirchner, 2005).

The non-reactive pollutant dispersion is evaluated with wind tunnel experimental data (Meroney et al., 1996). The experimental system consists of a single 2-D street canyon with $H / W=1$. The wind blows perpendicular to the canyon in $x$ direction and the emission source is located at the bottom of the domain. This scenario is similar to our 2-D CFD simulations with the exception of the cyclic boundary conditions imposed in a streamwise direction. In the comparison with experimental data, the inlet concentration is dismissed from the concentration inside the canyon. We focus on comparing pollutant concentrations from simulation results with the measurements of an urban roughness experimental case at different points close to walls within the canyon (Fig. 2). The concentration at each measurement point is normalized with respect to the concentration at point 7 within the street $\left(C / C_{7}\right)$. The same normalization was used in Santiago and Martín (2008) to evaluate the CFD model results with the

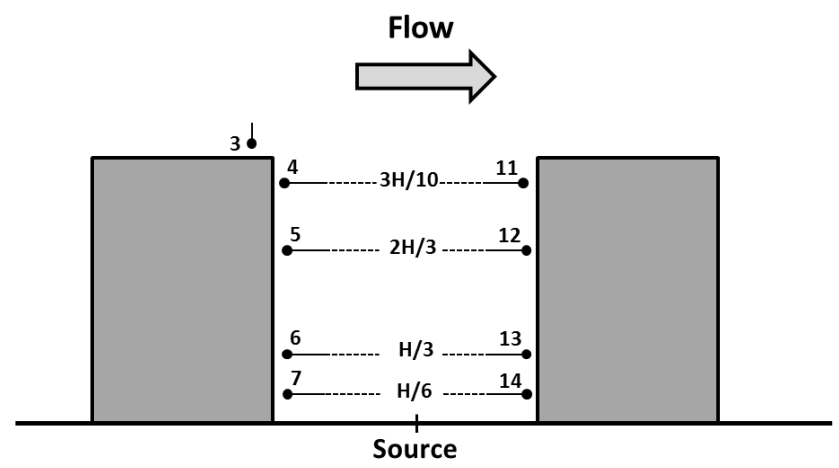

Figure 2. Location of the comparison points with the experimental measurements of Meroney et al. (1996)

same experiment. Comparison between the experimental and computed normalized concentration is depicted in Fig. 3.

Overall, a good agreement is obtained in spite of the slight difference at point 4 and 13, where the concentration is lower than the experimental data. Moreover, the linear regression concludes a good correlation $(R=0.92)$ between experimental measurements and simulated results. For further information, the statistical parameters of normalized mean square error (NMSE), fractional bias (FB), correlation $(R)$ and the fraction of predictions within a factor of 2 of observations (FAC2) are computed with the following the equations:

$\mathrm{NMSE}=\frac{\sum_{i=1}^{n}\left(O_{i}-P_{i}\right)^{2}}{\sum_{i=1}^{n}\left(O_{i} P_{i}\right)}$,

$\mathrm{FB}=\frac{\bar{O}-\bar{P}}{0.5(\bar{O}+\bar{P})}$,

$R=\frac{\sum_{i=1}^{n}\left[\left(O_{i}-\bar{O}\right)\left(P_{i}-\bar{P}\right)\right]}{\left[\sum_{i=1}^{n}\left(O_{i}-\bar{O}\right)^{2}\right]^{1 / 2}\left[\sum_{i=1}^{n}\left(P_{i}-\bar{P}\right)^{2}\right]^{1 / 2}}$,

$\mathrm{FAC} 2=$ fraction of data that satisfy $0.5 \leq P_{i} / O_{i} \geq 2$,

where $n$ is the number of points, the $O_{i}$ are the measurements at each point, and $\bar{O}$ is the measurement mean, and $P_{i}$ and $\bar{P}$ are the computed values at each point and its corresponding mean. The values of $\mathrm{FAC} 2=1, \mathrm{NMSE}=0.030$ and $\mathrm{FB}=0.068$ reveal a good fit between computed and experimental data with a slight underestimation. Therefore, the pollutant dispersion is accurately simulated in base to the model acceptance criteria established for NMSE $<1.5$ and $-0.3<\mathrm{FB}<0.3$ in Chang and Hanna (2005) and as a threshold of the correlation coefficient $R>0.8$ in Goricsán et al. (2011) (Table 3).

Second, the accuracy of solving a vast number of chemical reactions using the CFD model is evaluated with the chemical box model used to develop the CCM-CFD (Sect. 2). For this comparison, the CFD model was run as a box and the chemical evolution for the reactive species of the CCM- 
(a)
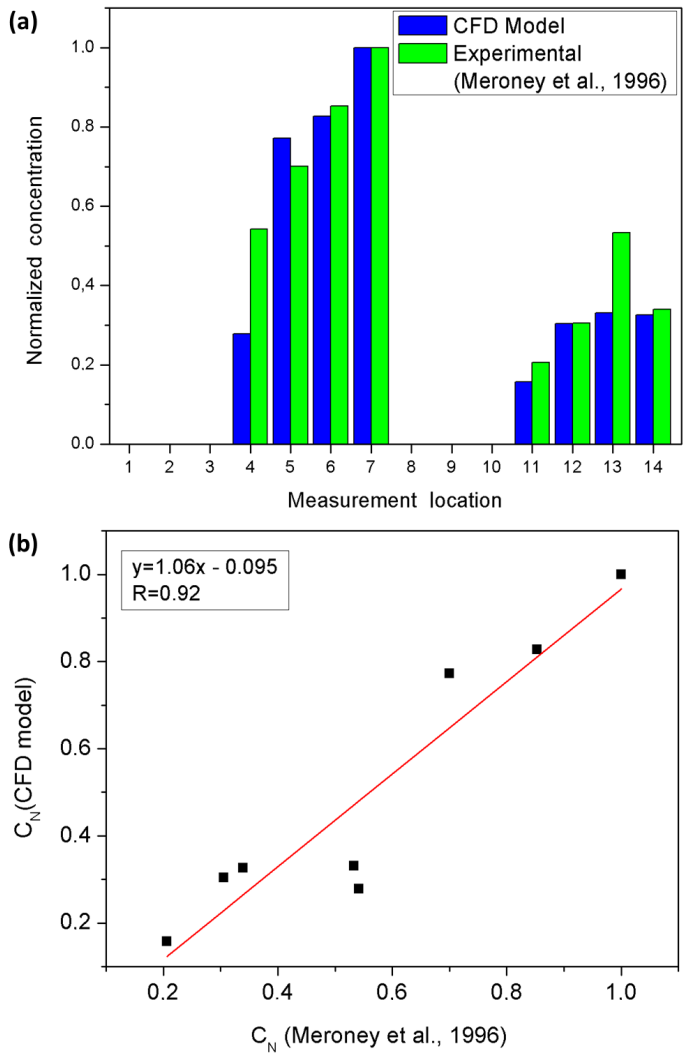

Figure 3. Comparison between simulation results and experimental data (Meroney et al., 1996). (a) Comparison between modeled concentration and experimental measurements at each location. (b) Linear fit between experimental measurements and modeled concentrations.

CFD is simulated for $30 \mathrm{~min}$. Similar initial conditions and the related traffic pollutant emission of an urban area are considered in this test. In both cases, the reaction rate and the photolysis rate constants are fixed using, $T=293 \mathrm{~K}$ and $\theta=40^{\circ}$. In a detailed assessment, the statistical parameters NMSE, FB, $R$ and the maximum relative concentration error from CFDs results with respect to the box-model results are calculated for all pollutants. The NMSE and FB indicate that the CFD results of concentration are quite similar to the box model results, with values on the order of $10^{-6}$ and $10^{-3}$, respectively, and the correlation is approximately 1 for all pollutants. Furthermore, for instance, the maximum relative error of concentration for $\mathrm{NO}, \mathrm{NO}_{2}$ and $\mathrm{O}_{3}$ is 0.28 , 0.18 and $0.085 \%$, respectively. These differences are mainly caused by numerical errors. Therefore, the implementation of the chemical terms in the transport equations in the CFD model is appropriately solved.

Last, the appropriate time step in order to solve the dynamic transport and the chemical reactions is evaluated using the CCM-CFD with $\mathrm{VOC} / \mathrm{NO}_{x}=1 / 2$ in 2-D geometry. The concentration of reactive pollutants is analyzed for different time steps $(0.1,1$ and $2 \mathrm{~s})$. During the first period of the
Table 3. Statistic metrics obtained for the validation of CFD results with experimental data (Meroney et al., 1996) and the acceptance criteria proposed by Chang and Hanna (2005) for urban configuration.

\begin{tabular}{lrr}
\hline & $\begin{array}{r}\text { Acceptance } \\
\text { criteria }\end{array}$ & $\begin{array}{r}\text { Statics } \\
\text { values }\end{array}$ \\
\hline NMSE & $<1.5$ & 0.03 \\
\hline FB & $(-0.3,0.3)$ & 0.068 \\
\hline$R$ & $>0.8$ & 0.92 \\
\hline
\end{tabular}

simulation, the turbulent dynamic is simulated at a time step of $1 \mathrm{~s}$, without including chemical interactions. After that, the chemical reactions are implemented in the CFD simulation carrying out every time step case $\left(t_{\mathrm{s}}=0.1 \mathrm{~s}, t_{\mathrm{s}}=1 \mathrm{~s}\right.$ and $t_{\mathrm{s}}=2 \mathrm{~s}$ ). Finally, when the steady state is reached, the horizontal spatial average concentrations of $\mathrm{NO}, \mathrm{NO}_{2}$ and $\mathrm{O}_{3}$ are compared in the whole domain. The deviation of concentration from the case with $t_{\mathrm{s}}=1 \mathrm{~s}$ is quantified using the quadratic relative differences given by

$\mathrm{QD}(\%)=\frac{\sqrt{\frac{1}{n} \sum_{k}^{n}\left(C_{k}^{\prime}-C_{k}\right)^{2}}}{\frac{1}{n} \sum_{k}^{n} C_{k}} \cdot 100$,

where $C_{k}^{\prime}$ and $C_{k}$ is the horizontal average concentration at several vertical levels with $t_{\mathrm{S}}=0.1$ or $2 \mathrm{~s}$ and $t_{\mathrm{s}}=1 \mathrm{~s}$, respectively. The results of the QD for $\mathrm{NO}, \mathrm{NO}_{2}$ and $\mathrm{O}_{3}$ from the simulations with the time step 0.1 and $2 \mathrm{~s}$ are enclosed in $\mathrm{Ta}-$ ble 4 . By comparing these results, we establish the time step at $1 \mathrm{~s}$ in order to simulate the dispersion of reactive pollutants.

\section{Results and discussion}

The CFD model is used to simulate turbulent flow and dispersion of reactive species in two different geometries: a 2-D street canyon and a 3-D staggered array of cubes. The interaction between the atmosphere and buildings configuration induces complex flow patterns within the urban canopy and this induces a heterogeneous pollutant distribution in the streets. Herein the canopy height is regarded as the height of buildings $(H)$. The ventilation of the street in a 2-D geometry is more reduced than in a 3-D geometry and, accordingly, pollutants reside longer in the street (Vardoulakis et al., 2003). Thus, the residence time of pollutants in the street is determined by building configurations and wind flow. The time that these pollutants remain within the street affects the chemical interactions, and, as a consequence, the amount of concentration at pedestrian level. For that reason, the effects of including chemical reactions in the CFD simulations are 


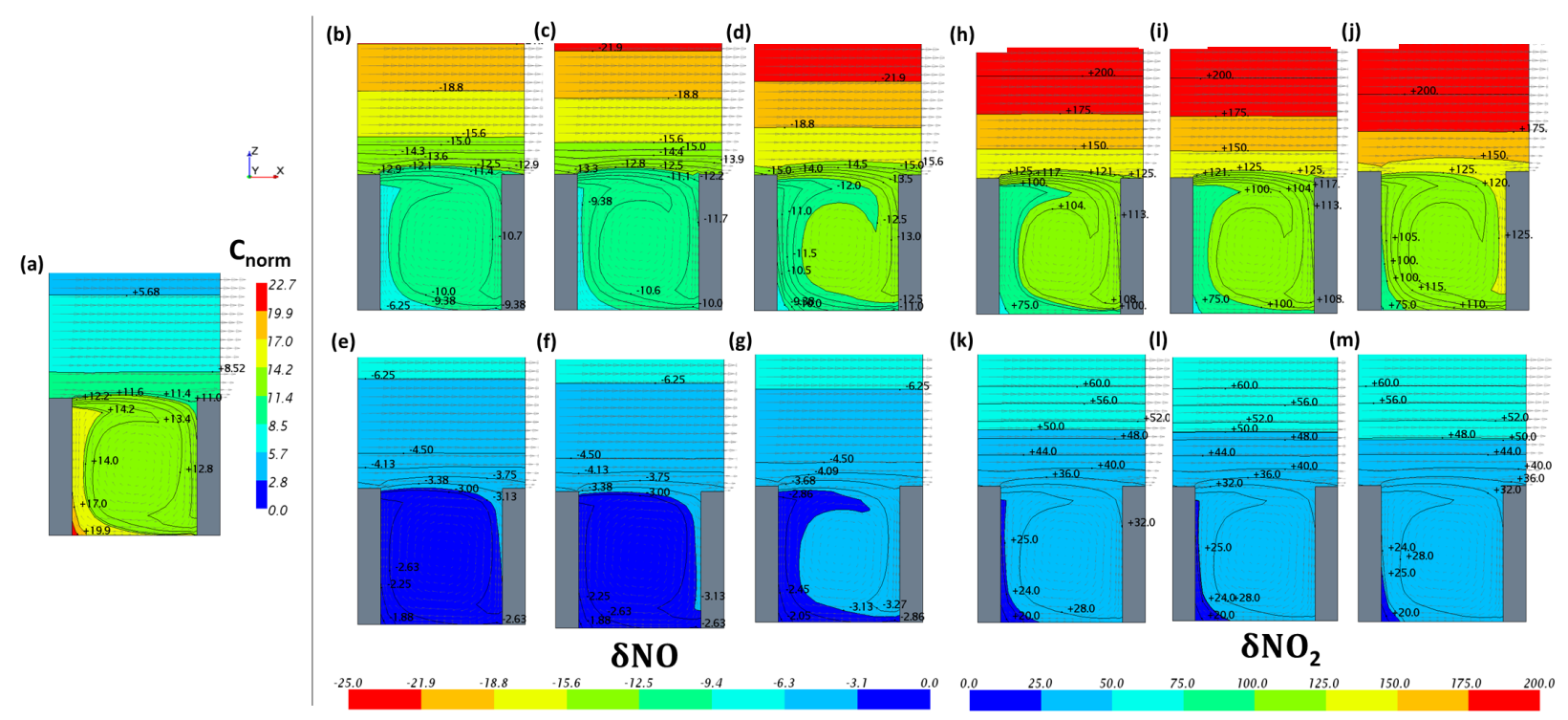

Figure 4. In the 2-D geometry: (a) distribution of the normalized concentration of tracer and (b-m) the $\delta \mathrm{NO}$ and $\delta \mathrm{NO}_{2}$ for PSS, CCM1/5 and CCM1/2 are respectively depicted in (b-d) and (h-j) for case 2 and in $(\mathbf{e}-\mathbf{g})$ and $(\mathbf{k}-\mathbf{m})$ for case 4.

Table 4. Quadratic relative differences of concentration different time step (\%).

\begin{tabular}{lrr}
\hline & $\mathrm{QD}\left(t_{\mathrm{s}}=0.1 \mathrm{~s}\right)$ & $\mathrm{QD}\left(t_{\mathrm{s}}=2 \mathrm{~s}\right)$ \\
\hline $\mathrm{NO}$ & 0.0061 & 0.023 \\
\hline $\mathrm{NO}_{2}$ & 0.0062 & 0.022 \\
\hline $\mathrm{O}_{3}$ & 0.0014 & 0.0055 \\
\hline
\end{tabular}

evaluated in 2-D and 3-D domains. To facilitate the analysis, the concentration of the study pollutants are normalized using the emission area $\left(A_{\mathrm{Em}}\right)$, the reference velocity $\left(u_{\tau}\right)$ and the source emission rate $(Q)$ given by

$C_{\mathrm{N}}=\frac{C u_{\tau} A_{\mathrm{Em}}}{Q}$.

This work is focused on analyzing $\mathrm{NO}$ and $\mathrm{NO}_{2}$ dispersion within the street and their normalized concentrations are referred to as $[\mathrm{NO}]_{\mathrm{N}}$ and $\left[\mathrm{NO}_{2}\right]_{\mathrm{N}}$. In addition, to quantify the effect of considering chemical reactions, the deviation in concentration $(\delta C)$ from the non-reactive compound behavior is computed as

$\delta C(\%)=\frac{C_{\mathrm{N}}-C_{\mathrm{N}}(T)}{C_{\mathrm{N}}(T)} \cdot 100$,

where $C_{\mathrm{N}}$ and $C_{\mathrm{N}}(T)$ are the normalized concentration of the pollutants regarded as reactive and non-reactive, respectively.

\subsection{Ozone influence on reactive pollutants}

The $\mathrm{O}_{3}$ concentration is generally dependent on the photochemical regime but in the street, it is also affected by chem- ical interactions with the $\mathrm{NO}_{x}$ and VOC levels owing to the VOC / $\mathrm{NO}_{x}$ traffic emission ratio. Kwak and Baik (2012) analyzed the effect of several $\mathrm{VOC} / \mathrm{NO}_{x}$ emission ratios with a background $\left[\mathrm{O}_{3}\right]$ fixed. In addition, with $\mathrm{VOC} / \mathrm{NO}_{x}$ fixed emission rates, the diurnal variation of $\mathrm{NO}_{x}$ and the exchange of $\mathrm{O}_{3}$ at roof level was studied in Kwak and Baik (2014). To further examine the influence of the available $\mathrm{O}_{3}$ on [NO] and $\left[\mathrm{NO}_{2}\right]$ in the street with several levels of VOC emission, two background $\left[\mathrm{O}_{3}\right]$ are considered: case 2 and case 4 (Table 2).

Figure 4 shows $\delta \mathrm{NO}$ and $\delta \mathrm{NO}_{2}$ in the 2-D geometry. In the case of lower $\left[\mathrm{O}_{3}\right]$ background, either considering the photostationary steady state (hereafter referred to as PSS) or the CCM-CFD with $\mathrm{VOC} / \mathrm{NO}_{x}$ emission ratio $1 / 5$ or $1 / 2$ (hereafter referred to as CCM1/5 and CCM1/2), $\delta \mathrm{NO}$ and $\delta \mathrm{NO}_{2}$ below the canopy top are around 3 and $30 \%$, respectively. This indicates that the reactions involving VOC have little impact on the $\mathrm{NO}$ and $\mathrm{NO}_{2}$ levels, whereas the $\mathrm{NO}_{x}-$ $\mathrm{O}_{3}$ reactions have a slightly major effect on $\left[\mathrm{NO}_{2}\right]$. On the other hand, in the higher $\mathrm{O}_{3}$ case, $\delta \mathrm{NO}$ and $\delta \mathrm{NO}_{2}$ increase on average to nearly $12.5 \%$ and more than $100 \%$ within the street, respectively, and furthermore the difference of including VOC reactions is remarkable. As a result, in the higher $\mathrm{O}_{3}$ case and high VOC emission, the $\left[\mathrm{NO}_{2}\right]$ and $[\mathrm{NO}]$ in the street is respectively underestimated and overestimated with the PSS in comparison with the results including the VOC reactions.

The $[\mathrm{NO}]_{\mathrm{N}}$ and $\left[\mathrm{NO}_{2}\right]_{\mathrm{N}}$ from PSS, CCM1/5 and CCM1/2 are compared in normalized concentration with their corresponding non-reactive pollutant below the canopy top in the 2-D and 3-D geometries. Figure 5 illustrates the vertical profiles of the horizontal spatial average of $[\mathrm{NO}]_{\mathrm{N}}$ and $\left[\mathrm{NO}_{2}\right]_{\mathrm{N}}$ 
(a)

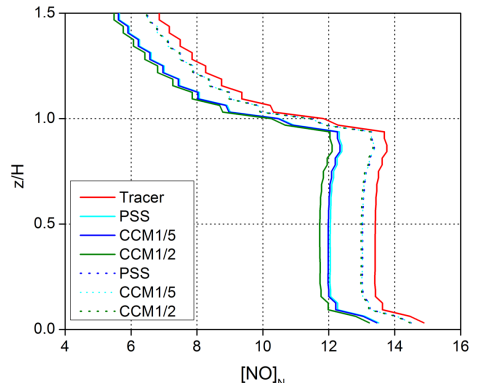

(c)

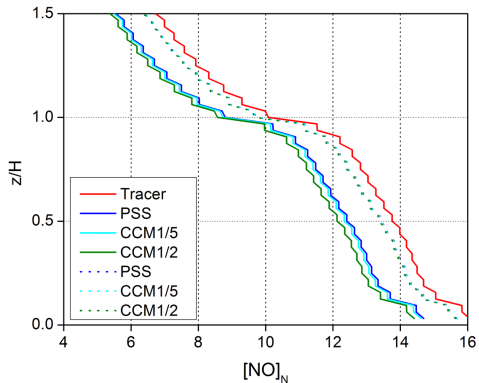

(b)

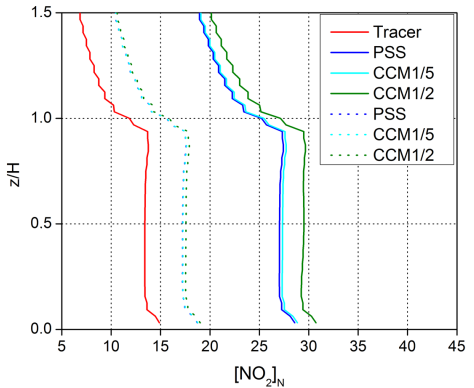

(d)

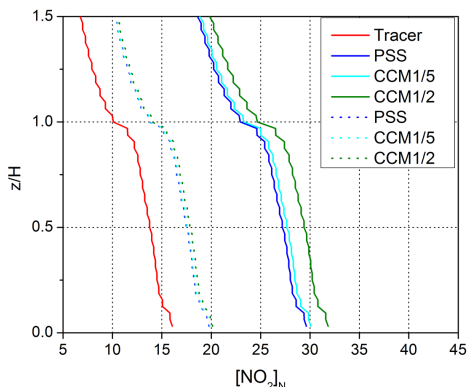

Figure 5. Vertical profiles of horizontal spatial average of $[\mathrm{NO}]_{\mathrm{N}}$ and $\left[\mathrm{NO}_{2}\right]_{\mathrm{N}}$ for all chemical scenarios in case 2 (solid line) and case 4 (dotted line) in both geometries: 2-D (a, b) and 3-D (c, d).

for the two $\mathrm{O}_{3}$ cases. In the lower $\mathrm{O}_{3}$ case, the difference between chemical scenarios is negligible in both computational configurations. Overall, the variation of $[\mathrm{NO}]_{\mathrm{N}}$ and $\left[\mathrm{NO}_{2}\right]_{\mathrm{N}}$ among PSS, CCM1/5 and CCM1/2 are bounded on 0.05 and $2.3 \%$, which represents a maximum deviation of 0.3 and $1.3 \mathrm{ppb}$ in absolute concentration within the street, respectively. In contrast, in the higher $\mathrm{O}_{3}$ case, the importance of the photochemical reactions increases. In 2-D geometry, with the PSS, CCM1/5 and CCM1/2, the $[\mathrm{NO}]_{\mathrm{N}}$ is respectively about $10.1,10.5$ and $12.3 \%$ less than the normalized tracer concentration within the canopy in the street canyon geometry. Likewise in the 3-D geometry, the $[\mathrm{NO}]_{\mathrm{N}}$ for all mechanisms are shifted around 10-12\% from non-reactive pollutants. Focusing on $\left[\mathrm{NO}_{2}\right]_{\mathrm{N}}$ including VOC reactions against the $\mathrm{NO}_{x}-\mathrm{O}_{3}$ system, $\mathrm{NO}_{2}$ is more affected by the increase of the background $\mathrm{O}_{3}$ and the photochemical reactions owing to the zenith angle of summer. The $\left[\mathrm{NO}_{2}\right]_{\mathrm{N}}$ rises more than $15 \%$ with CCM1/2, which represents values of up to $10 \mathrm{ppb}$ in the 2-D configuration and $7 \mathrm{ppb}$ in the staggered array of cubes. Therefore, in both geometries, the $\left[\mathrm{O}_{3}\right]$ of background and the solar position $(\theta)$ regarded in photolysis rates highlight the effect of including more chemical reactions on the study of $\mathrm{NO}$ and $\mathrm{NO}_{2}$ dispersion in the street.

In addition, the difference among chemical mechanisms is also influenced by VOC levels. In the lower $\mathrm{O}_{3}$ case, the effect of VOC emission has a minimum impact on $[\mathrm{NO}]_{\mathrm{N}}$ and $\left[\mathrm{NO}_{2}\right]_{\mathrm{N}}$. This is due to the selected zenith angle being representative of winter conditions; therefore, the photolysis constants are smaller than that given in a representative summer case. This implies that the background $\mathrm{O}_{3}$ concentration computed by the photochemical equilibrium equation is low. In turn, the VOC oxidation cycle is also limited by the photolysis of some VOCs. Furthermore, given that the $\mathrm{NO}_{x}$ emission dominates over the VOC emission, the high levels of $\mathrm{NO}_{x}$ concentration tend to inhibit $\mathrm{O}_{3}$ formation and limit the $\mathrm{O}_{3}$ production through VOC reactions. Therefore, the difference in $\mathrm{NO}$ and $\mathrm{NO}_{2}$ concentration after including VOC reactions against the photostationary steady state is negligible in this low- $\mathrm{O}_{3}$ case. So the weak dependence on VOC concentration is a combination of the low $\mathrm{O}_{3}$ and small photolysis rates; therefore, the PSS or a more complex chemical mechanism can be used to reproduce the $\mathrm{NO}$ and $\mathrm{NO}_{2}$ dispersion in the street since the results are quite similar. However, in the representative summer case with high VOC levels, the reactions involving VOC are more important and larger differences in $[\mathrm{NO}]$ and $\left[\mathrm{NO}_{2}\right]$ with respect to $\mathrm{NO}_{x}-\mathrm{O}_{3}$ system are found. For instance in 2-D geometry, $[\mathrm{NO}]_{\mathrm{N}} /[\mathrm{NO}(T)]_{\mathrm{N}}$ is $0.87,0.89$ and 0.90 , whereas $\left[\mathrm{NO}_{2}\right]_{\mathrm{N}} /\left[\mathrm{NO}_{2}(T)\right]_{\mathrm{N}}$ varies from 2.18, 2.03 and 2.01 for CCM1/2, CCM1/5 and PSS, respectively. Concluding that taking into account the VOC reactions, the $\mathrm{NO}$ production is reduced and $\mathrm{NO}_{2}$ retrieval is increased in comparison to the results from the PSS owing to the degradation of VOC. This effect is remarkable in the higher $\left[\mathrm{O}_{3}\right]$ case and high VOC traffic emission.

\subsection{Wind speed influence on reactive pollutants}

The concentration of a non-reactive pollutant is inversely proportional to wind speed (Parra et al., 2010), but the nonlinearity of chemical reactions induces changes in this behavior. The effect due to wind speed on $\mathrm{NO}$ and $\mathrm{NO}_{2}$ dispersion is obtained considering two wind speeds changing the refer- 


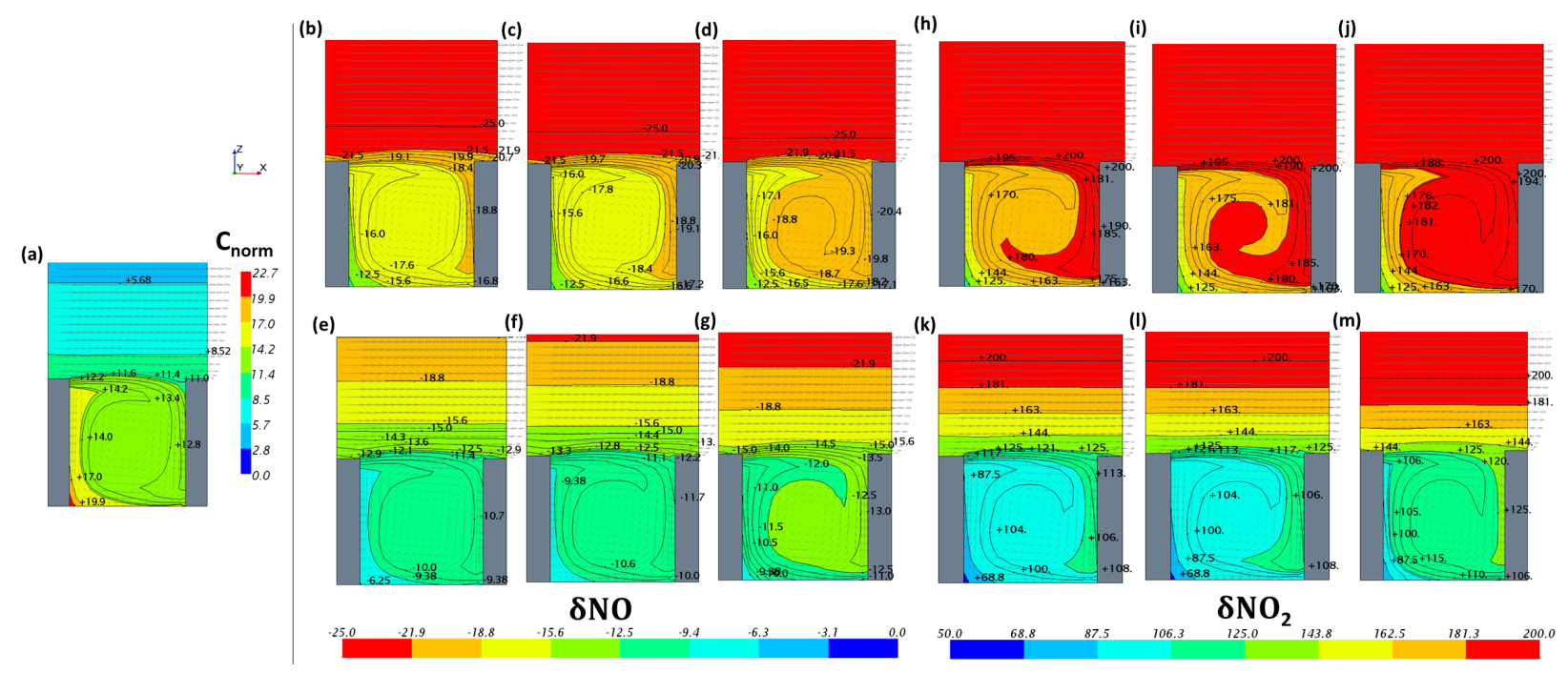

Figure 6. In the 2-D geometry: (a) distribution of normalized concentration of tracer and (b-m) the $\delta \mathrm{NO}^{2}$ and $\delta \mathrm{NO}_{2}$ for the PSS, CCM1/5 and CCM1/2 are respectively depicted in $(\mathbf{b}-\mathbf{d})$ and $(\mathbf{h}-\mathbf{j})$ for case 1 and in $(\mathbf{e}-\mathbf{g})$ and $(\mathbf{k}-\mathbf{m})$ for case 2.

ence velocity $\left(u_{\tau}\right)$ : case 1 and case 2 (Table 2 ). As discussed in the previous section, the higher $\mathrm{O}_{3}$ case is used in this section given that chemical reactions have more effect on $\mathrm{NO}$ and $\mathrm{NO}_{2}$ concentrations below the canopy top.

Figure 6 shows the $\delta \mathrm{NO}$ and $\delta \mathrm{NO}_{2}$ for different values of wind speed in the 2-D-geometry. In the faster wind speed case, the differences on normalized concentration are larger in comparison to the tracer behavior. Overall, for all chemical scenarios, $[\mathrm{NO}]_{\mathrm{N}}$ is reduced from the tracer around 18 and $10 \%$ within the canopy with $u_{\tau}=0.45 \mathrm{~m} \mathrm{~s}^{-1}$ and $u_{\tau}=$ $0.23 \mathrm{~m} \mathrm{~s}^{-1}$, respectively. However, the $\left[\mathrm{NO}_{2}\right]_{\mathrm{N}}$ increases a factor 2.7 and 2 from the normalized tracer concentration for $u_{\tau}=0.45 \mathrm{~m} \mathrm{~s}^{-1}$ and $u_{\tau}=0.23 \mathrm{~m} \mathrm{~s}^{-1}$, respectively. Therefore, greater influence of chemical reactions on $\mathrm{NO}$ and $\mathrm{NO}_{2}$ dispersion is obtained with the faster wind speed since it increases the $\mathrm{O}_{3}$ inflow to the street acting as a trigger between pollutant interactions. Note that for a tracer, the normalized concentration is proportional to concentration and inversely proportional to wind speed. However, the behavior of the normalized concentration of a reactive pollutant is not lineal with the wind speed.

To analyze the $[\mathrm{NO}]$ and $\left[\mathrm{NO}_{2}\right]$ within the canopy, the vertical profiles of horizontal spatial average of the normalized concentration in the 2-D and 3-D geometries are depicted in Fig. 7. Different vertical distributions of the normalized concentration are obtained for each geometry. However, the same deviation of the normalized concentrations including chemical reactions from its corresponding tracer is obtained in the 2-D and 3-D geometries with different wind speed. In the faster wind speed case, the normalized concentration tends to be further from the non-reactive normalized concentration; however, the variation among chemical scenarios is small. The $[\mathrm{NO}]_{\mathrm{N}}$ and $\left[\mathrm{NO}_{2}\right]_{\mathrm{N}}$ with $\mathrm{CCM} 1 / 2$ just differ from PSS around 1 and $7 \%$, respectively. In contrast, with lower wind speed, the $\left[\mathrm{NO}_{2}\right]_{\mathrm{N}}$ with CCM1/2 and CCM1/5 increases 17 and $2 \%$, respectively, from the PSS. In this case, the accumulation of $\mathrm{NO}_{x}$ emission within the street is greater, which contributes to quickly consume the $\left[\mathrm{O}_{3}\right]$, reducing the $\mathrm{NO}_{2}$ production and the $\mathrm{NO}$ removal. Likewise, the VOC levels given by the emission increase in the street intensify the $\mathrm{NO}_{2}$ production and $\mathrm{NO}$ depletion, developing the opposite effect. This means that the concentration from reactive pollutants is higher with faster wind speeds since it produces a greater exchange of pollutants between the street and overlying air. Whereas when the wind speed is reduced, the difference from tracer behavior is reduced but, the importance of reactions involving VOC increases in comparison with just regarding the $\mathrm{NO}_{x}-\mathrm{O}_{3}$ system.

\subsection{Vertical transport}

The vertical transport of $\mathrm{NO}, \mathrm{NO}_{2}$ and $\mathrm{O}_{3}$ is analyzed in both geometries in order to determine the atmospheric conditions from which the use of VOC reactions is needed to accurately reproduce the $\mathrm{NO}$ and $\mathrm{NO}_{2}$ dispersion within the street. With this analysis, it is possible to understand how either wind speed or the background of $\left[\mathrm{O}_{3}\right]$ affect on pollutants concentration. Figure 8 shows the average of the deviation of $[\mathrm{NO}]_{\mathrm{N}}$ and $\left[\mathrm{NO}_{2}\right]_{\mathrm{N}}$ below the canopy top in comparison to their corresponding tracer in each geometry (Eq. 9). For all cases simulated, the similar deviation of $\mathrm{NO}$ and $\mathrm{NO}_{2}$ from its tracer is obtained in both geometries.

In the lower $\mathrm{O}_{3}$ case, the differences on $\delta \mathrm{NO}$ and $\delta \mathrm{NO}_{2}$ among chemical mechanisms in 2-D geometry are negligible even with different wind speeds. For all chemical scenarios, $\delta \mathrm{NO}$ is around 5 and $3 \%$ for $u_{\tau}=0.45 \mathrm{~m} \mathrm{~s}^{-1}$ and $u_{\tau}=0.23 \mathrm{~m} \mathrm{~s}^{-1}$, respectively. However, in the higher $\mathrm{O}_{3}$ 
(a)

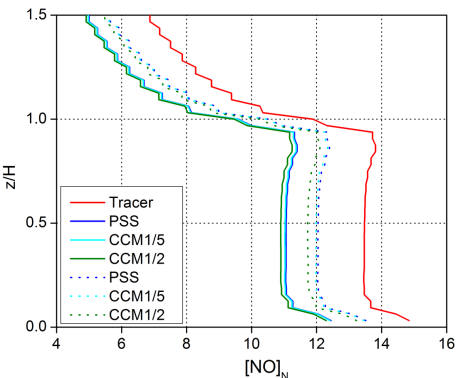

(c)

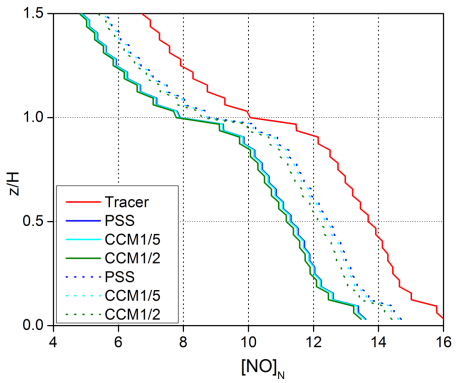

(b)

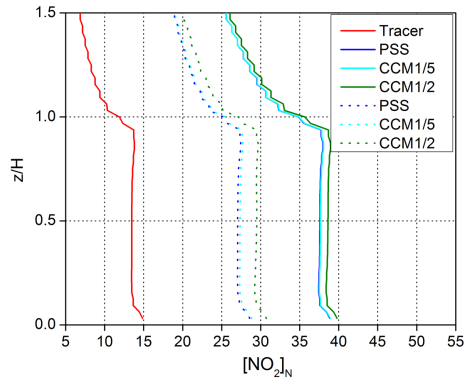

(d)

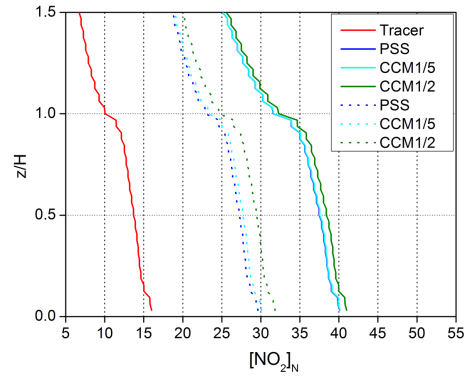

Figure 7. Vertical profiles of horizontal spatial average of $[\mathrm{NO}]_{\mathrm{N}}$ and $\left[\mathrm{NO}_{2}\right]_{\mathrm{N}}$ for all chemical scenarios in case 1 (solid line) and case 2 (dotted line) in both geometries: 2-D (a, b) and 3-D (c, d).

conditions, the differences of the simple scheme, and by including VOC reactions, are greater and the dependency on the wind speed is significant. As it has seen before, despite of the deviation in comparison with tracer is larger with the $u_{\tau}=0.45 \mathrm{~m} \mathrm{~s}^{-1}$, the higher differences between chemical scenarios are obtained with $u_{\tau}=0.23 \mathrm{~m} \mathrm{~s}^{-1}$. The maximum differences on $[\mathrm{NO}]_{\mathrm{N}}$ and $\left[\mathrm{NO}_{2}\right]_{\mathrm{N}}$ are obtained with more VOC emission, and their variation switch from 10 to $20 \%$ when the inflow velocity changes of $u_{\tau}=0.45 \mathrm{~m} \mathrm{~s}^{-1}$ to the half. Therefore, the chemical reactions are strongly determined by the available $\mathrm{O}_{3}$ of background and subsequently, they have an slight dependency with the wind speed.

With the objective to study the exchange of ozone inflow into the street in depth, the vertical fluxes are analyzed. Given that, there are only small differences between both computational domains with the same aspect ratio $H / W=1$. The pollutant removal from the street and pollutant entrainment into the street are analyzed by means of vertical fluxes of $\mathrm{NO}, \mathrm{NO}_{2}$ and $\mathrm{O}_{3}$ in the 3-D geometry. The total vertical flux $\left(F_{\mathrm{T}, i}\right)$ is defined as a sum of vertical mean flux $\left(F_{\mathrm{m}, i}\right)$ and turbulent flux $\left(F_{\mathrm{t}, i}\right)$. The horizontal spatial average $(<>)$ of $F_{\mathrm{T}, i}$ of $i$ th species is computed at several vertical levels every $1 \mathrm{~m}$ using the following equations:

$F_{\mathrm{T}, i}=<\overline{w C}>=F_{\mathrm{m}, i}+F_{\mathrm{t}, i}$,

$F_{\mathrm{m}, i}=<\bar{w} \overline{C_{i}}>$,

$F_{\mathrm{t}, i}=<\overline{w^{\prime} C_{i}^{\prime}}>=-K_{c} \frac{\partial C_{i}}{\partial z}$.

Here $w$ and $w^{\prime}$ are the vertical velocity and its fluctuation with respect to the mean, $\bar{w}$, and $C_{i}$ and $C_{i}^{\prime}$ are the corre- sponding variables to the concentration of $i$ th species. To examine the atmospheric parameters effect on $\mathrm{NO}$ and $\mathrm{NO}_{2}$ with regard to reactive pollutants through vertical fluxes, the $\mathrm{NO}$ and $\mathrm{NO}_{2}$ fluxes are normalized following the method developed for a passive tracer in Martilli et al. (2013). For a passive tracer, taking into account an homogeneous emission at the surface, the steady state and neglecting vertical variations of air density with height, the following holds, within the canopy (Eq. 13) and above (Eq. 14),

$$
\begin{aligned}
& <\overline{w^{\prime} C^{\prime}}>+<\bar{w} \bar{C}>=S, \\
& <\overline{w^{\prime} C^{\prime}}>+<\bar{w} \bar{C}>=S \frac{A_{\text {street }}}{A_{\text {street }}+A_{\text {roof }}},
\end{aligned}
$$

where $S$ is the constant emission flux at the surface and $A_{\text {street }}$ and $A_{\text {roof }}$ are the areas of the streets and roofs of buildings, respectively. Hereafter, the spatial horizontal average of total fluxes of $\mathrm{NO}$ and $\mathrm{NO}_{2}$ are normalized with $S$ (within the canopy) and $S A_{\text {street }} /\left(A_{\text {street }}+A_{\text {roof }}\right)$ above, referred to as $<\overline{w \mathrm{NO}}>_{\mathrm{N}}$ and $<\overline{w \mathrm{NO}_{2}}>_{\mathrm{N}}$.

Figure 9 illustrates the vertical profiles of the deviation of $<\overline{w \mathrm{NO}}>_{\mathrm{N}},<\overline{w \mathrm{NO}_{2}}>_{\mathrm{N}}$ from the normalized total flux of tracer and the vertical profile of $<\overline{w \mathrm{O}_{3}}>$ spatially averaged for the CCM1/2 and PSS scenarios in the 3-D geometry. The CCM1/5 results are not shown since their results are quite similar to PSS results. The $<\overline{w \mathrm{NO}}>_{\mathrm{N}}$ and $<\overline{w \mathrm{NO}_{2}}>_{\mathrm{N}}$, taking into account chemical reactions, are compared with the normalized flux of tracer. The vertical transport of a tracer above the canopy top is only turbulent, given that the mean vertical velocity is zero, but within the canopy in the middle part, it is mainly dominated by mean flux. This behavior is obtained for $\mathrm{NO}$ and $\mathrm{NO}_{2}$ and are regarded as reactive pol- 
(a)

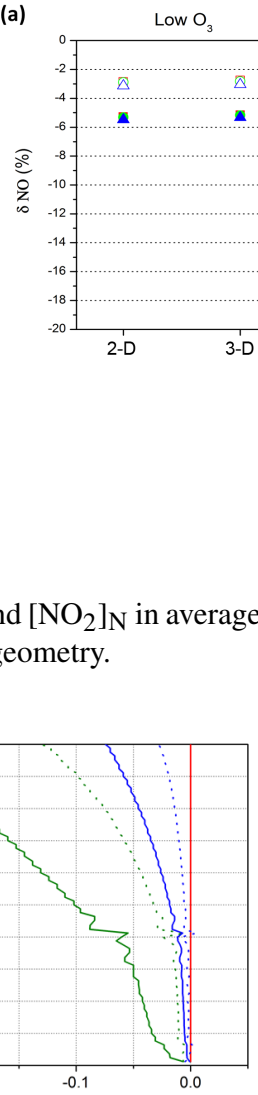

(d)
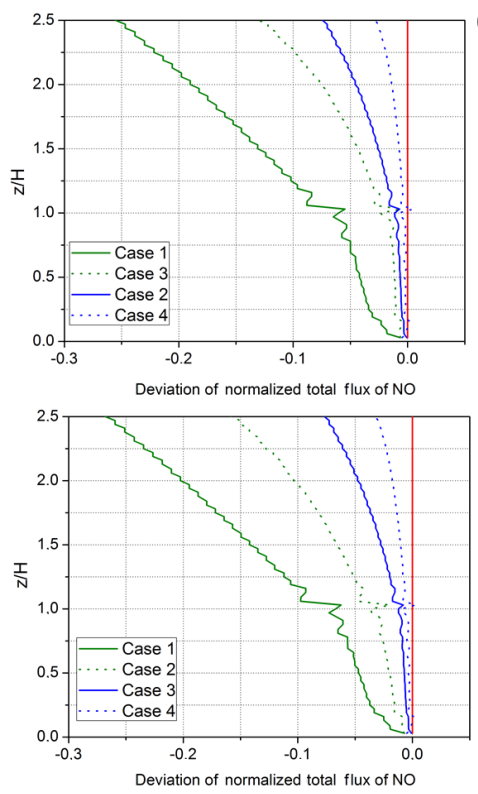

(b)

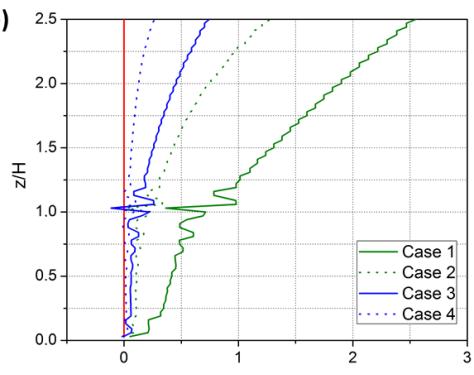

(e)

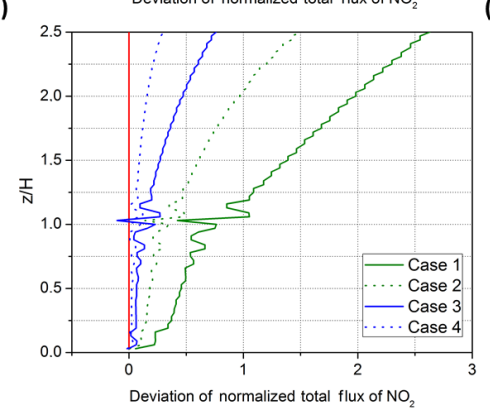

(c)

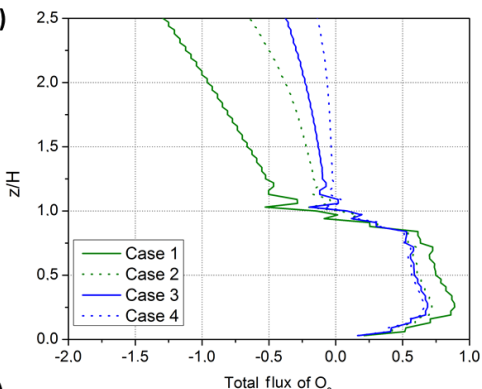

(f)

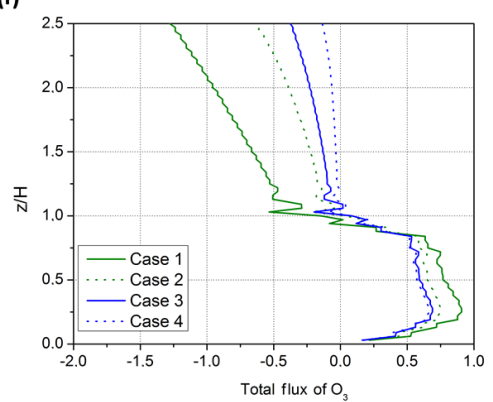

Figure 9. Vertical profiles of the deviation of $<\overline{w \mathrm{NO}}>_{\mathrm{N}}$ and $<\overline{w \mathrm{NO}_{2}}>_{\mathrm{N}}$ from the normalized total flux of tracer and the $<\overline{w \mathrm{O}_{3}}>\mathrm{N}$ for the (a-c) PSS and (d-f) CCM1/2 in the 3-D geometry for all study cases. The red line is the normalized total flux of the tracer.

lutants as well. Unlike the tracer fluxes, the turbulent fluxes of $\mathrm{NO}$ and $\mathrm{NO}_{2}$ are affected by chemical interactions, mainly with $\mathrm{O}_{3}$. In Fig. 9, we can observe that the effect of the chemical reactions involving VOC (with the $\mathrm{VOC} / \mathrm{NO}_{x}=1 / 2$ ) on vertical transports of $\mathrm{NO}$ and $\mathrm{NO}_{2}$ are significant in the higher $\left[\mathrm{O}_{3}\right]$ and faster wind speed case. In this case, the $<\overline{w \mathrm{NO}}>_{\mathrm{N}}$ and $<\overline{w \mathrm{NO}_{2}}>_{\mathrm{N}}$ are slightly smaller and larger, respectively, corresponding to a greater vertical transport of $\mathrm{O}_{3}$ in all heights and more photochemical activity. In contrast, in the other cases, the influence of introducing chemical reactions on $<\overline{w \mathrm{NO}}>_{\mathrm{N}}$ and $<\overline{w \mathrm{NO}_{2}}>_{\mathrm{N}}$ can be observed just above the canopy top, whereas within the street is quite similar to the tracer flux. That is due to fact that the
$\left[\mathrm{O}_{3}\right]$ is practically depleted by reaction with NO before entering into the street. Furthermore, the strong NO emission and lower wind speed avoid the escape of NO from the street and block the $\mathrm{O}_{3}$ formation by means of degradation reactions of VOC. That means that in the higher $\mathrm{O}_{3}$ case with the faster wind speed, the downward motion contributes to introduce $\left[\mathrm{O}_{3}\right]$ into the street and the upward motion to remove the $[\mathrm{NO}]$ from the street; moreover, the VOC emission benefits the conversion of $\mathrm{NO}$ to $\mathrm{NO}_{2}$. Therefore, the impact of the reactions involving VOC with the emission ratio $\mathrm{VOC} / \mathrm{NO}_{x}=1 / 2$ on $[\mathrm{NO}]$ and $\left[\mathrm{NO}_{2}\right]$ is significant in the street. 


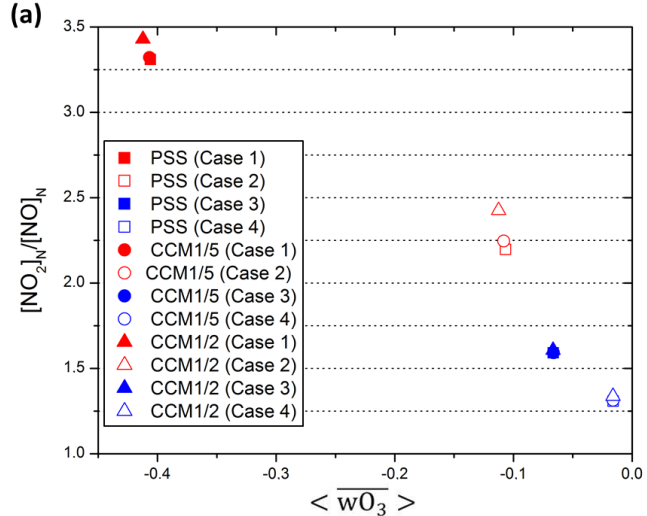

(b)

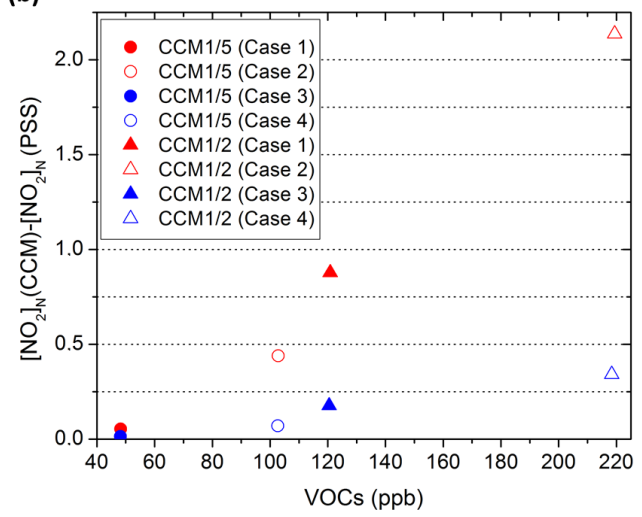

Figure 10. (a) The average concentration within the canopy of $\left[\mathrm{NO}_{2}\right]_{\mathrm{N}} /[\mathrm{NO}]_{\mathrm{N}}$ against the total flux of $\mathrm{O}_{3}$ at roof level and $(\mathbf{b})$ the variation of the average concentration within the canopy of $\left[\mathrm{NO}_{2}\right]_{\mathrm{N}}$ with CCM1/5 and CCM1/2 from that the PSS over the average concentration of VOC.

For a better understanding of the relative importance of including more chemical reactions and so to characterize the $\mathrm{NO}$ and $\mathrm{NO}_{2}$ dispersion under several conditions, the effect on $[\mathrm{NO}]_{\mathrm{N}}$ and $\left[\mathrm{NO}_{2}\right]_{\mathrm{N}}$ within the canopy is analyzed considering jointly all variables studied here. In this way, the variability of vertical transport of $\mathrm{O}_{3}$ and, in turn, the effect of VOC emission linked to the change of wind speed is examined. Figure 10a shows the averaged concentration within the canopy of $\left[\mathrm{NO}_{2}\right]_{\mathrm{N}}$ over $[\mathrm{NO}]_{\mathrm{N}}$ in relation to the total flux of $\mathrm{O}_{3}$ at roof level $\left(<\overline{w \mathrm{O}_{3}}>_{\mathrm{N}}\right)$ for the PSS and CCM1/5 and $\mathrm{CCM} 1 / 2$ in the ozone and wind speed cases. Note that $\left[\mathrm{NO}_{2}\right]_{\mathrm{N}} /[\mathrm{NO}]_{\mathrm{N}}$ is 1 for the non-reactive species. Thus, the deviation from 1 indicates the effect of chemical reactions. Figure $10 \mathrm{~b}$ illustrates the variation of considering VOC reactions aside from the $\mathrm{NO}_{x}-\mathrm{O}_{3}$ reactions by means of $\left[\mathrm{NO}_{2}\right]_{\mathrm{N}}$ with respect to the increase of VOC average concentration below the canopy top.

In Fig. 10a we can observe that the effect of chemical reactions is greater in the higher $\mathrm{O}_{3}$. With faster wind speed, the inflow of $\mathrm{O}_{3}$ to the street increases owing to the downward motion and for that, the value of $\left[\mathrm{NO}_{2}\right]_{\mathrm{N}} /[\mathrm{NO}]_{\mathrm{N}}$ is large. On the other hand, when the $\left[\mathrm{O}_{3}\right]$ levels are not enough to react with large $\mathrm{NO}_{x}$ emission and the photochemical reactions are slower, the difference on $[\mathrm{NO}]_{\mathrm{N}}$ and $\left[\mathrm{NO}_{2}\right]_{\mathrm{N}}$ with respect to the normalized concentration tracer is smaller $\left(\left[\mathrm{NO}_{2}\right]_{\mathrm{N}} /[\mathrm{NO}]_{\mathrm{N}}<1.75\right)$. Focusing on the lower $\mathrm{O}_{3}$ case, the variation among chemical scenarios is negligible. However, higher differences are found on $\left[\mathrm{NO}_{2}\right]_{\mathrm{N}} /[\mathrm{NO}]_{\mathrm{N}}$ by increasing the inflow of $\left[\mathrm{O}_{3}\right]$ into the street. The deviation on $\left[\mathrm{NO}_{2}\right]_{\mathrm{N}}$ after including VOC reactions against the photostationary steady state is analyzed in Fig. 10b. The slight variations among chemical scenarios is caused by VOC levels. Although the results conclude that small differences exist in winter conditions, they are insignificant since the maximum deviation is $1 \mathrm{ppb}$ corresponding to the slow velocity for $\mathrm{CCM} 1 / 2$. In contrast, in the summer case, with high $\left[\mathrm{O}_{3}\right]$, the variations between chemical scenarios are greater and increase with the VOC emission in the street. This is due to the slower wind speed, which induces less vertical exchange and avoids the exit of VOC concentration from the street. In fact the higher VOC emission under these conditions benefits the VOC reaction, which induce the conversion of NO to $\mathrm{NO}_{2}$, increasing the difference with respect to the $\mathrm{NO}_{x}-\mathrm{O}_{3}$ reactions.

In summary, the impact of the chemical reactions below the canopy top is affected by the $\mathrm{O}_{3}$ entrainment within the canopy, and this is directly proportional to the value of $\mathrm{O}_{3}$ above the canopy top and the wind speed. On the other hand, the VOC reactions are more important in the canopy under high $\mathrm{O}_{3}$ and high VOC levels. The second depends on the emission ratio and the upward VOC flux at the top of the canopy. For that, stronger winds will increase the flux, and so reduce the importance of the VOC reactions in the canopy.

\section{Summary and conclusions}

The purpose of this work is to optimize the modeling of $\mathrm{NO}$ and $\mathrm{NO}_{2}$ dispersion with respect to chemical reactions over a real urban area. Accordingly, an analysis of the relative importance of chemical reactions with respect to mean and turbulent transport has been carried out by means of a CFD model. This is based on three different model setups: a simulation where chemical reactions are not considered (passive tracer), one where only the $\mathrm{NO}_{x}-\mathrm{O}_{3}$ cycle is simulated (Photostationary steady state) and the last one where the reactions involving VOC are also implemented (a complex chemical mechanism reduced for the CFD model). With normalized concentration the source emission dependency is dismissed, and the deviation with respect to tracer is only due to the chemical reactions of pollutants with each other. Furthermore, this helps to extract the conclusion in the 2-D and 3 -D configurations used without dependence on geometry.

As it can be seen in this study, the general conclusions linked to the use of chemical reactions are obtained from both geometries. The solar position and the available $\mathrm{O}_{3}$ within 
the canopy determine the impact on $\mathrm{NO}$ and $\mathrm{NO}_{2}$ concentration in the street on including chemical reactions. Additionally, the influence of wind speed is evaluated in order to establish a relation of $[\mathrm{NO}]$ and $\left[\mathrm{NO}_{2}\right]$ with $\left[\mathrm{O}_{3}\right]$ below the canopy. The wind speed defines the vertical transport in the domain and consequently, the inflow of $\mathrm{O}_{3}$ into the street. Based on this, the higher differences of $[\mathrm{NO}]_{\mathrm{N}}$ and $\left[\mathrm{NO}_{2}\right]_{\mathrm{N}}$ on the tracer are obtained with faster wind speed in the higher $\left[\mathrm{O}_{3}\right]$ of the background case. That is due to a major vertical exchange of concentration that intensifies the $\mathrm{NO}_{x}$ removal and the $\mathrm{O}_{3}$ entrainment in the street. However, in the winter representative case when the amount of $\mathrm{O}_{3}$ is generally lower, the variation of wind speed has hardly any influence on $[\mathrm{NO}]_{\mathrm{N}}$ and $\left[\mathrm{NO}_{2}\right]_{\mathrm{N}}$.

Given that the VOC are also emitted in traffic exhausts, two real emission ratios of $\mathrm{VOC} / \mathrm{NO}_{x}$ are considered (VOC $/ \mathrm{NO}_{x}=1 / 2$ and $\left.\mathrm{VOC} / \mathrm{NO}_{x}=1 / 5\right)$. The vertical fluxes of concentration and the average concentration below the canopy under several atmospheric conditions show the deviation of $[\mathrm{NO}]_{\mathrm{N}}$ and $\left[\mathrm{NO}_{2}\right]_{\mathrm{N}}$ by including VOC reactions against to the $\mathrm{NO}_{x}-\mathrm{O}_{3}$ system. With high available ozone in the street, the difference between chemical schemes is intensified by increasing the amount of VOC emission. The lower wind speed conditions encourages the increment of VOC within the canopy and this bears relation to the NO reduction and $\mathrm{NO}_{2}$ production, the canopy and the chemical interactions increase the $\mathrm{NO}$ conversion into $\mathrm{NO}_{2}$. Likewise, the formation of $\mathrm{O}_{3}$ related to the photolysis of $\mathrm{NO}_{2}$ along with the $\mathrm{O}_{3}$ concentration of background increase the difference on the $\left[\mathrm{NO}_{2}\right]_{\mathrm{N}}$ considering the VOC reactions with respect to the simple chemical mechanism.

Presently, the big concern about air quality in big cities has encouraged many studies about dispersion of the primary pollutants related to traffic emission. It focuses on $\mathrm{NO}_{2}$ since it is the most detrimental for citizens health. To simulate its dispersion in a real urban area is a big challenge from the perspective of modeling at microscale with a CFD model. To obtain the best compromise between accuracy and the CPU time required in order to simulate the $\mathrm{NO}_{2}$ dispersion within the streets, this work seeks the chemical reactions needed as a function of several atmospheric conditions. In winter conditions when the $\mathrm{O}_{3}$ concentration within the canopy is usually below $5 \mathrm{ppb}$ and the solar radiation is low, the implementation of $\mathrm{NO}_{x}-\mathrm{O}_{3}$ reactions can be suitable with slight errors. For instance, the $[\mathrm{NO}]_{\mathrm{N}}$ and $\left[\mathrm{NO}_{2}\right]_{\mathrm{N}}$ for $\mathrm{CCM} 1 / 2$ and CCM1/5 differ from the PSS by less than $2 \%$. Even with a low wind speed, the behavior of $[\mathrm{NO}]_{\mathrm{N}}$ and $\left[\mathrm{NO}_{2}\right]_{\mathrm{N}}$ on average is quite close to that tracer. In contrast when the amount of the available $\mathrm{O}_{3}$ within the street increases to more than $10 \mathrm{ppb}$ within the canopy, the differences linked to the chemical reactions considered rises. The nonlinearity of chemistry induces that $[\mathrm{NO}]$ and $\left[\mathrm{NO}_{2}\right]$ are not inversely proportional with respect to wind speed, unlike the non-reactive pollutant. Moreover, the VOC levels within the street is also an important factor to take into account. With conditions of high background $\mathrm{O}_{3}$ concentration, and with an emission ratio of $\operatorname{VOC} / \mathrm{NO}_{x}=1 / 2$, the $[\mathrm{NO}]_{\mathrm{N}}$ and $\left[\mathrm{NO}_{2}\right]_{\mathrm{N}}$ increase the error with respect to PSS more than $16 \%$; hence, the VOC chemical reactions seem to be necessary in order to reproduce the $\mathrm{NO}$ and $\mathrm{NO}_{2}$ dispersion in the streets. These assumptions can be useful and provide information to study pollutant dispersion in real urban areas using a CFD model.

\section{Data availability}

The model outputs are not available at a publicly accessible database but they will be provided on request (beatriz.sanchez@ciemat.es). They are archived in the CIEMAT server, which assures that the data are stored for the next years.

Author contributions. Beatriz Sanchez performed the CFD simulations. Beatriz Sanchez, Jose-Luis Santiago and Alberto Martilli discussed the results from the CFD simulations and the conclusions. Magdalena Palacios reviewed the chemical comments. Frank Kirchner developed the complex chemical mechanism implemented in the CFD model. Beatriz Sanchez prepared the manuscript with contributions from all co-authors.

Acknowledgements. This study has been supported by European Project LIFE MINOx-STREET (LIFE12 ENV/ES/000280) funded by EU. Authors thank Extremadura Research Centre for Advanced Technologies (CETA-CIEMAT) for allowing us to use its computing facilities for the simulations. CETA-CIEMAT belongs to CIEMAT and the Government of Spain and is funded by the European Regional Development Fund (ERDF).

Edited by: S. Galmarini

Reviewed by: two anonymous referees

\section{References}

Ayuntamiento-Madrid: Inventario de emisiones de contaminantes a la atmósfera en el municipio de Madrid 1999-2012, Area de Gobierno de Medio Ambiente y Movilidad del Ayuntamiento de Madrid, Spain, available at: http://www.madrid.es/UnidadesDescentralizadas/ Sostenibilidad/EspeInf/EnergiayCC/04CambioClimatico/ 4aInventario/Ficheros/InventarioEAM2012.pdf (last access: 26 September 2016), 2014 (in Spanish).

Baik, J.-J., Kang, Y.-S., and Kim, J.-J.: Modeling reactive pollutant dispersion in an urban street canyon, Atmos. Environ., 41, 934949, 2007.

Baker, J., Walker, H. L., and Cai, X.: A study of the dispersion and transport of reactive pollutants in and above street canyons - a large eddy simulation, Atmos. Environ., 38, 6883-6892, 2004.

Bright, V. B., Bloss, W. J., and Cai, X.: Urban street canyons: Coupling dynamics, chemistry and within-canyon chemical processing of emissions, Atmos. Environ., 68, 127-142, 2013. 
Buccolieri, R., Salim, S. M., Leo, L. S., Di Sabatino, S., Chan, A., Ielpo, P., de Gennaro, G., and Gromke, C.: Analysis of local scale tree-atmosphere interaction on pollutant concentration in idealized street canyons and application to a real urban junction, Atmos. Environ., 45, 1702-1713, 2011.

Buckingham, C.: London atmospheric emissions inventory, London Research Centre, 1997.

Chang, C.-H. and Meroney, R. N.: Concentration and flow distributions in urban street canyons: wind tunnel and computational data, J. Wind Eng. Ind. Aerod., 91, 1141-1154, 2003.

Chang, J. C. and Hanna, S. R.: Technical descriptions and user's guide for the BOOT statistical model evaluation software package, Version 2.0, available at: http://www.harmo.org/ kit/Download/BOOT_UG.pdf (last access: 26 September 2016), 2005.

Coceal, O., Thomas, T., Castro, I., and Belcher, S.: Mean flow and turbulence statistics over groups of urban-like cubical obstacles, Bound.-Lay. Meteorol., 121, 491-519, 2006.

Galmarini, S., Vilà-Guerau De Arellano, J., and Duynkerke, P.: Scaling the turbulent transport of chemical compounds in the surface layer under neutral and stratified conditions, Q. J. Roy. Meteor. Soc., 123, 223-242, 1997.

Goricsán, I., Balczó, M., Balogh, M., Czáder, K., Rákai, A., and Tonkó, C.: Simulation of flow in an idealised city using various CFD codes, Int. J. Environ. Poll., 44, 359-367, 2011.

Junier, M., Kirchner, F., Clappier, A., and van den Bergh, H.: The chemical mechanism generation programme CHEMATA - Part 2: Comparison of four chemical mechanisms for mesoscale calculation of atmospheric pollution, Atmos. Environ., 39, 11611171, 2005.

Kim, J.-J. and Baik, J.-J.: A numerical study of the effects of ambient wind direction on flow and dispersion in urban street canyons using the RNG $k-\varepsilon$ turbulence model, Atmos. Environ., 38, 3039-3048, 2004.

Kim, M. J., Park, R. J., and Kim, J.-J.: Urban air quality modeling with full $\mathrm{O}_{3}-\mathrm{NO}_{x}$-VOC chemistry: Implications for $\mathrm{O}_{3}$ and PM air quality in a street canyon, Atmos. Environ., 47, 330-340, 2012.

Kirchner, F.: The chemical mechanism generation programme CHEMATA - Part 1: The programme and first applications, Atmos. Environ., 39, 1143-1159, 2005.

Kwak, K.-H. and Baik, J.-J.: A CFD modeling study of the impacts of $\mathrm{NO}_{x}$ and $\mathrm{VOC}$ emissions on reactive pollutant dispersion in and above a street canyon, Atmos. Environ., 46, 71-80, 2012.

Kwak, K.-H. and Baik, J.-J.: Diurnal variation of NO x and ozone exchange between a street canyon and the overlying air, Atmos. Environ., 86, 120-128, 2014.

Kwak, K.-H., Baik, J.-J., and Lee, K.-Y.: Dispersion and photochemical evolution of reactive pollutants in street canyons, Atmos. Environ., 70, 98-107, 2013.
Martilli, A., Santiago, J. L., and Salamanca, F.: On the representation of urban heterogeneities in mesoscale models, Environ. Fluid Mech., 15, 305-328, 2013.

Meroney, R. N., Pavageau, M., Rafailidis, S., and Schatzmann, M.: Study of line source characteristics for 2-D physical modelling of pollutant dispersion in street canyons, J. Wind Eng. Ind. Aerod., 62, 37-56, 1996.

Molemaker, M. J. and Vilà-Guerau de Arellano, J.: Control of chemical reactions by convective turbulence in the boundary layer, J. Atmos. Sci., 55, 568-579, 1998.

Park, S.-B., Baik, J.-J., Raasch, S., and Letzel, M. O.: A large-eddy simulation study of thermal effects on turbulent flow and dispersion in and above a street canyon, J. Appl. Meteorol. Clim., 51, 829-841, 2012.

Park, S.-J., Kim, J.-J., Kim, M. J., Park, R. J., and Cheong, H.-B.: Characteristics of flow and reactive pollutant dispersion in urban street canyons, Atmos. Environ., 108, 20-31, 2015.

Parra, M., Santiago, J., Martín, F., Martilli, A., and Santamaría, J.: A methodology to urban air quality assessment during large time periods of winter using computational fluid dynamic models, Atmos. Environ., 44, 2089-2097, 2010.

Santiago, J. and Martilli, A.: A dynamic urban canopy parameterization for mesoscale models based on computational fluid dynamics Reynolds-averaged Navier-Stokes microscale simulations, Bound.-Lay. Meteorol., 137, 417-439, 2010.

Santiago, J. and Martín, F.: SLP-2D: A new Lagrangian particle model to simulate pollutant dispersion in street canyons, Atmos. Environ., 42, 3927-3936, 2008.

Santiago, J., Krayenhoff, E., and Martilli, A.: Flow simulations for simplified urban configurations with microscale distributions of surface thermal forcing, Urban Clim., 9, 115-133, 2014.

Seinfeld, J. H. and Pandis, S. N.: Atmospheric chemistry and physics: from air pollution to climate change, John Wiley \& Sons, 1998.

Stockwell, W. R., Kirchner, F., Kuhn, M., and Seefeld, S.: A new mechanism for regional atmospheric chemistry modeling, J. Geophys. Res.-Atmos., 102, 25847-25879, 1997.

Tominaga, Y. and Stathopoulos, T.: Numerical simulation of dispersion around an isolated cubic building: model evaluation of RANS and LES, Build. Environ., 45, 2231-2239, 2010.

Vardoulakis, S., Fisher, B. E., Pericleous, K., and Gonzalez-Flesca, N.: Modelling air quality in street canyons: a review, Atmos. Environ., 37, 155-182, 2003. 